\title{
Subjective well-being: Keeping up with the perception of the Joneses.
}

\author{
Cahit Guven * \\ Deakin University University of Houston and CEPR \\ Bent E. Sørensen ${ }^{\dagger}$
}

July 2011

\begin{abstract}
Using data from the U.S. General Social Survey 1972-2004, we study the role of perceptions and status in self-reported happiness. Reference group income negatively relates to own happiness and high perceptions about own relative income, quality of dwelling, and social class relate positively and very significantly to happiness. Perceptions about income and status matter more for females, and for low income, conservative, more social, and less trusting individuals. Dwelling perceptions matter more for males, and for middle income, married, conservative, more social, and less trusting individuals.
\end{abstract}

FIGURES: 3

TABLES: 10

WORDS:9597

JEL Classification: D14, D63, I31,

Keywords: happiness, social comparison, status, perceptions.

${ }^{*}$ Deakin University, Melbourne, Victoria, Australia

${ }^{\dagger}$ Department of Economics, University of Houston, TX, 77204, e-mail: bent.sorensen@mail.uh.edu, tel: 713 7433841, fax: 713 7433798. The authors thank several referees and participants at the International Conference on Policies for Happiness in Sienna, the $76^{\text {th }}$ Annual SEA Meetings, the $11^{\text {th }}$ Texas Econometrics Camp, the $7^{\text {th }}$ Annual Missouri Economics Conference, and seminar participants at Sam Houston State University and the University of Houston for their valuable comments and suggestions. Special thanks to Rainer Winkelmann. 


\section{Introduction}

"Happiness is not achieved by the conscious pursuit of happiness; it is generally the byproduct of other activities." Aldous Leonard Huxley (July 26, 1894 - November 22, 1963) British philosopher.

We study self-reported happiness which we also refer to as "subjective well-being" using data from the U.S. General Social Survey (GSS) 1972-2004 which has surveyed about 3000 individuals annually or biennially since 1970!1 The GSS provides self-reported measures of well-being; i.e., responses to questions about how happy individual respondents are with their lives.

The economics profession has been wary of attempts to use measures of happiness in spite of the ubiquitous use of utility functions. We follow the convention of reserving the term "utility" for describing individuals' choices between economic variables; however, self-reported well-being is related to "utility" in the sense that well-being helps predict individuals' economic choices; see the survey by Frey and Stutzer (2002). Higher income allows people to purchase more goods which is expected to increase well-being but people also derive happiness from high relative income. Luttmer (2005) shows that well-being depends on relative consumption in addition to absolute consumption in the United States. He uses income as a proxy for consumption and finds that neighbors' income has a significant negative influence on individual well-being. In addition, Clark and Oswald (1996) find that workers' reported satisfaction is inversely related to their comparison wage rates. However, Clark et al. (2009) find a positive relationship between neighborhood income and happiness, consistent with findings in Senik (2009). Clark and Senik (2010) find that, in Europe, colleagues are the most frequently-cited reference group for income comparisons.

We find that income relative to individuals' own cohort working in the same occupation group and living in the same region matters for happiness.$^{2}$ We then investigate the unexplored issue of whether or not the perception of relative income matters in addition to actual

\footnotetext{
${ }^{1}$ The GSS is in transition from a replication cross-sectional design to a design that uses rotating panels. In 2008 there were two components: a new 2008 cross-section with 2,023 cases and the first re-interviews with 1,536 respondents from the 2006 GSS, however these data are not available yet but will be available in the future.

${ }^{2}$ We tried different reference groups such as people living in the same region. To save space, we do not report these results. See Senik (2009) and Rablen (2008) for more discussion on income comparisons and the choice of reference groups.
} 
relative income. We do not have exogenous shifters of perceptions so terms like "matters" should not be understand in a causal sense but only as a predictive correlation. In the GSS, unlike most other surveys, individuals are asked their opinion about their income relative to an average American family and their opinion about what social class they belong to. We show that perceptions about relative income are highly correlated with happiness. After controlling for own income and reference group income, higher perceptions about relative income predict higher happiness. If people care about their relative standing in the society, social class may be important and, indeed, we find that perceived social class is highly positively correlated with happiness while actual social class is of little importance.

We consider perceived dwelling status as a predictor of happiness and find that perceptions about own dwelling, relative to others in the city and neighborhood, matter for happiness, even after controlling for dwelling ownership, dwelling type, and various neighborhood characteristics. Perceived dwelling status relative to others in the neighborhood is more important than perceptions about dwellings in the broader city. Because people typically observe neighborhood residences more than other residences in the city, this strengthens the conclusion that relative, rather than absolute, status matters.

Perceptions about relative income are more important for individuals who still live in the city in which they grew up ("non-movers"), females, and conservatives as well as low income individuals while perceived social class matters more for and conservatives. Perceptions about one's dwelling are more important in explaining happiness for non-movers, males, and conservatives. Inequality aversion lessens the influence of income and social class perceptions but strengthens the impact of dwelling perceptions. The results are robust to selection, different sub-samples, selection of reference group, controlling for income and happiness shocks, and estimation techniques.

Section 2 gives an overview of the literature on happiness and Section 3 discusses the data and the construction of the variables used in the paper. Section 4 presents the basic framework and the estimation strategy while Section 5 presents descriptive statistics. Section 6 presents the empirical results of the paper and Section 7 concludes. The Appendix gives more detailed information about the GSS and the variables used. In the Appendix, we also display and discuss the results from a battery of robustness regressions. 


\section{Related literature}

Oswald (1997) shows that happiness with life is rising in the United States but the increase is small - it seems that extra income is not contributing much to the quality of peoples' lives. Since the early 1970s, reported levels of satisfaction with life in European countries have, on average, risen very slightly and other scholars have found that the proportion of people considering themselves to be "very happy" has fallen over the same time period, in spite of increasing income levels. Recently, Graham (2004) argues that absolute income matters up to a certain point - particularly when basic needs are not met - but after that, relative income matters more.

Adaptation and social comparison are possible explanations why increases in absolute income are not reflected in happiness. In a recent study, Di Tella et al. (2010) find strong adaptation to changes in income in Germany but not to changes in status. In sub-samples, they find no adaptation to income for males, right-wingers, and self-employed but females, left-wingers, and employees show adaptation to income. However, the latter group do not show adaptation to status.

Many economists have noted that individuals compare themselves to others with respect to income, consumption, status, or utility. In other words, relative income may matter more than actual income; see the survey by Clark et al. (2008). Van Praag and Kapteyn (1973) construct an econometrically estimated welfare function with a "preference shift" parameter that captures the tendency of material wants to increase as income increases. They find that increases in income shift aspirations upward and this preference shift destroys about 60 to 80 percent of the welfare effect of an increase in income.

High income aspirations may also be formed during childhood. Winkelmann et al. (2007c) find a negative externality of parental income on children's current well-being with children comparing their actual income with the acquired aspiration level. There are a number of reasons why an interpretation based chiefly on "relativity" notions is plausible. A certain amount of empirical support has been developed for the relative income concept in other economic applications, such as savings behavior and, more recently, fertility behavior and labor force participation (Duesenberry, 1949; Easterlin, 1963, 1973; Freedman, 1963; Wachter, 1972, 1974).

Economists have identified a U-shaped relationship between age and happiness (Oswald 
1997, Blanchflower and Oswald, 2000). For several reasons, it is difficult to capture the influence of age on well-being. The term happiness may change its meaning with age and the age effect may interfere with a cohort effect. The direction of causation is also unclear because happy people tend to live longer which contributes to a positive correlation between age and happiness. Happiness and health are highly correlated and Wright (1985) finds an effect of self-rated health on satisfaction which is not affected by comparison with others.

Blacks tend to be less happy than whites in all psychological and sociological studies in the United States. This also holds for other countries such as South Africa, where whites are happiest followed by Indians, coloreds, and blacks (Moller, 1989). A major reason for lower subjective well-being of blacks may be lower self-esteem, which in turn may be caused by lower status in society. Economists have also found that American blacks are less happy than whites (Blanchflower and Oswald, 2000).

The level of education bears little relationship to happiness. Education may indirectly contribute to happiness by allowing for a better adaptation to changing environments but it also tends to raise aspiration levels. It has, for instance, been found that highly educated are more distressed than less educated when hit by unemployment (Clark and Oswald, 1994).

\section{Data}

We use GSS data from 1972 to 2004. The GSS consists of cross-sectional surveys conducted by the National Opinion Research Center (NORC) in the United States annually 1972-1994, except for the years 1979, 1981, and 1992, and biennially beginning in 1994. The main areas covered in the GSS include socioeconomic status, social mobility, social control, family, race relations, sexual relations, civil liberties, and morality. Our dependent variable is the response to the question, "Taken all together, how would you say things are these dayswould you say that you are very happy, pretty happy, or not too happy?" The response is recoded as a categorical variable taking the values 1,2 , and 3 which in order refers to "not too happy," "pretty happy," and "very happy." (The answers "don’t know," "no answer," and "not applicable" are recorded as missing.) As shown in Figure 1, there is substantial variation in respondents' happiness levels. 32 percent of the respondents are "very happy," 56 percent are "pretty happy," while 12 percent are "not too happy."

In the GSS, income is a categorical variable taking values $1-13$ where 13 is the highest 
income level. In order to calculate relative income, we use the midpoint method $\bigsqcup^{3}$ The lowest and the highest income values in a category are known and we calculate each household's income as the midpoint income of that category, normalized by the Consumer Price Index (CPI). In the regressions, we use actual income as a continuous variable but because perceived relative income is a categorical variable with 5 categories, we also recode actual income into 5 categories in order to make it comparable.

Reference group income is the average income of a reference group. We tried reference groups with different ranges for age, region, and occupational sector (one and three digit sectors and occupations) and chose the group which provides the best fit in the regressions. The reference group used in the regressions is the individuals' own cohort working in the same occupation group (one digit) and living in the same region. In the regressions, we use reference group income as a continuous variable but we also recode reference group income into 5 categories. People know their own current actual income but they may not have current information about others' current income. In this case, reference group income may be the lagged average reference group income. We therefore attempte to use the income of the reference group in the previous period as well.

Perceived relative income is the answer to the question, "Compared with American families in general, would you say your family income is far below average, below average, average, above average, or far above average?" This variable has 5 categories: "far below average," "below average," "average," "above average," and "far above average." ("Don’t know," "no answer," and "not applicable" are recorded as missing.) In the regressions, we use perceived relative income as a categorical variable but since actual relative income is a continuous variable, we also use perceived relative income as a continuous variable taking values from 1 through 5 . There is substantial variation in perceived relative income as shown in Figure 1. 5 percent of the sample are "far below average," 24 percent "below average," 51 percent "average," 19 percent "above average," and 2 percent "far above average."

Perceived social class is the answer to the question, "If you were asked to use one of four names for your social class, which would you say you belong in: the lower class, the working class, the middle class, or the upper class?" This variable has 4 categories: "lower class," "working class," "middle class," and "upper class." (The answers "don't know," "no

\footnotetext{
${ }^{3} \mathrm{GSS}$ also created its own household income variable which is available in the dataset and we checked our results with this variable as well.
} 
answer," and "not applicable" are recorded as missing .) In the regressions, we use perceived social status as a categorical variable but since occupational prestige and socio-economic index are used as the control variables and are continuous variables, we also use perceived social status as a continuous variable taking values from 1 through 4 to make it comparable. As shown in Figure 1, 5 percent of the sample are "lower class," 46 percent "working class," 46 percent "middle class," and 3 percent "upper class."

Perceptions about dwelling relative to other dwellings in the city and the neighborhood are the answers to the questions 1) "Compared to apartments/houses in the neighborhood, would you say the house/apartment is far below average, below average, average, above average, or far above average?" and 2) "Compared to apartments/houses in the city/town/county, would you say the house was far below average, below average, average, above average, or far above average?" The answers take values 1-5 which corresponds to "far below average," "below average," "average," "above average," and "far above average." We control for the type of the dwelling in the regressions which is coded as follows: Trailer (1), detached single family house (2), 2-family house, 2 units side by side (3), 2-family house, 2 units one above the other (4), detached 3-4 family house (5), row house (6), apartment house, 3 stories or less (7), apartment house, 4 stories or more (8), apartment in a partly commercial structure (9), other (10). We also control for the dwelling ownership which is the answer to the question "(Do you/does your family) own your (home/apartment), pay rent, or what?" Answers are coded as follows: "own or is buying," "pays rent," and "other." The distribution of the perceptions about dwellings compared to houses in the city are similar to a normal distribution as shown in Figure 1 while perceptions relative to neighborhood are more clustered around the middle value. Around 71 percent of individuals in the sample consider their dwelling "average" relative to others in the neighborhood but this number is only 57 percent relative to others in the city.

Socio-Economic Index scores are originally calculated by Otis Dudley Duncan based on NORC's North-Hatt prestige study. Duncan regresses prestige scores for 45 occupational titles on education and income to produce weights that would predict prestige. This algorithm is then used to calculate socio-economic index scores for all occupational categories employed in the Census classification of occupations. Similar procedures have been used to produce socio-economic scores based on later NORC prestige studies and censuses.

Regions: New England, Middle Atlantic, East North Central, West North Central, South 
Atlantic, East South Central, West South Central, Mountain, Pacific, Foreign. Sectors: Agriculture, Construction, Mining, Manufacturing, Transportation, Retail Trade, Wholesale, Finance, Entertainment, Public Administration. For further details and the exact definitions of other variables used, see the Appendix.

\section{Empirical Framework}

In the empirical analysis, we estimate self-reported happiness of an individual $i$ at time $t$ as a function of his/her logarithm (ln) reference group income and ln household income together with the following control variables: dwelling ownership, ln weekly working hours, labor force status, sex, age, age squared, race, years of education, ln household size, marital status, religion, In population of the place of residence, region fixed effects, year fixed effects, occupation fixed effects, and industry fixed effects. We estimate an OLS model for selfreported happiness (on a scale 1-3) $]^{4}$ to make the interpretation of the coefficients easy; however, we report ordered probit estimates in the robustness tables in the Appendix. The coefficients from the OLS regression are presented with robust standard errors. We use logarithmic values of the variables in the regressions. However, we also consider levels in the robustness part, as well as nonlinearities, by recoding main variables into categories. ln reference group income is the average income of people who live in the same region, work in the same occupation category (1-digit) and are of the same age as the respondent. The following equation is our baseline regression and is estimated for the whole sample and separately for married and nonmarried individuals:

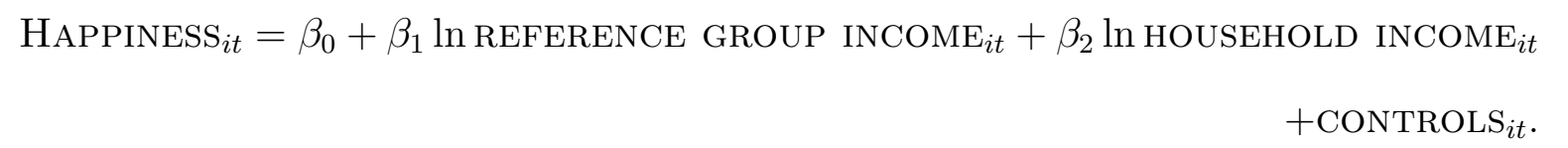

We estimate self-reported happiness of an individual $i$ at time $t$ as a function of his/her ln occupational prestige, ln perceived relative income, ln reference group income, and $\ln$ household income together with the same control variables mentioned above. Perceived relative income takes the values 1-5 and is treated as a continuous variable while occupational prestige takes values 0-100 where higher values correspond to higher occupational

\footnotetext{
${ }^{4}$ Frijters and Ferrer-i-Carbonell (2003) show that for self-reported happiness, OLS and ordered probit estimates give quite similar results.
} 
prestige. Further, we include perceptions about one's own social class in explaining his/her happiness - perceived social class takes values 1-4 and is treated as a continuous variable. We estimate the following equation (including perceived income, prestige, and social class one-by-one):

$$
\begin{array}{r}
\text { HAPPINESS }_{i t}=\beta_{0}+\beta_{1} \ln \text { REFERENCE GROUP INCOME } i t \\
+\beta_{3} \ln \text { PERCEIVED RELATIVE INCOME } \\
+ \text { INOUSEHOLD INCOME }_{i t}+\beta_{4} \ln _{2} \text { OCCUPATIONAL PRESTIGE }_{i t} \\
+\beta_{5} \ln \text { PERCEIVED SOCIAL CLASS }_{i t}+\text { CONTROLS }_{i t} .
\end{array}
$$

Next, we consider the role of perceptions about one's own dwelling compared to other dwellings in his/her city or neighborhood. We estimate self-reported happiness of an individual $i$ at time $t$ as a function of his/her ln perceived dwelling status with respect to other dwellings in his/her city, type of his/her dwelling as a categorical variable, ln perceived social class, ln occupational prestige, ln perceived relative income, ln reference group income and ln household income together with the same control variables mentioned above. Perceived dwelling status (city) takes values 1-5 and is treated as a continuous variable in the estimation. We use ln values of the variables in the regressions. However, we also consider levels in the robustness part, as well as nonlinearities, by recoding main variables into categories. We present the OLS coefficients from the following equation:

$$
\begin{aligned}
& \text { HAPPINESS }_{i t}=\beta_{0}+\beta_{1} \ln \text { REFERENCE GROUP } \text { INCOME }_{i t}+\beta_{2} \ln \text { HOUSEHOLD INCOME }_{i t} \\
& +\beta_{3} \ln \text { PERCEIVED RELATIVE INCOME } i t+\beta_{4} \ln \text { OCCUPATIONAL PRESTIGE }_{i t} \\
& +\beta_{5} \ln \text { PERCEIVED SOCIAL CLASS } i t+\beta_{7} \text { DWELLING TYPE }_{i t} \\
& +\beta_{6} \ln \text { PERCEIVED DWELling StATUS (CITY OR NEIGHBORHOOd) }{ }_{i t}+\text { CONTROLS } i t .
\end{aligned}
$$

We allow for potential non-monotonicity in our analysis and estimate self-reported happiness of an individual $i$ at time $t$ as a function of his/her perceived dwelling status with respect to other dwellings in his/her city as a 5 category variable, perceived social class as a 4 category variable, perceived relative income as a 5 category variable, reference group income and household income as a 5 category variable which are recoded from the original data, together with the same control variables mentioned above. We estimate self-reported 
happiness of an individual $i$ at time $t$ as a function of his/her perceived dwelling status with respect to other dwellings in his/her city or neighborhood as a 5 category variable as coded in the codebook, type of his/her dwelling, perceived social class as a 4 category variable as coded in the codebook, perceived relative income as a 5 category variable as coded in the codebook, reference group income and household income as a 5 category variable which are recoded in to 5 categories from the original, together with the same control variables mentioned above.

The impact of perception may co-vary with gender, income, and other characteristics of respondents and we examine this issue using interaction effects. We label the variables, such as gender, as $Z_{i t}$ and each of our perception variables as $P_{i t}$. For each choice of $P, Z$ we estimate the following equation:

$$
\begin{aligned}
& \text { HAPPINESS }_{i t}=\beta_{0}+\beta_{1} \ln \text { REFERENCE GROUP INCOME } i t+\beta_{2} \ln \text { HOUSEHOLD INCOME }_{i t} \\
& +\beta_{3} \ln \text { PERCEIVED RELATIVE INCOME } i t+\beta_{4} \ln \text { OCCUPATIONAL PRESTIGE }_{i t} \\
& +\beta_{5} \ln \text { PERCEIVED SOCIAL CLASS } i t+\beta_{6} \ln \text { PERCEIVED DWELLING STATUS }(\text { CITY })_{i t} \\
& +\beta_{7} \ln \text { PERCEIVED DWELling StATUs (NEIGHBORHOOD) } i t+\beta_{8} \text { DWELLING TYPE }_{i t} \\
& +\beta_{9} \mathrm{Z}_{i t}+\beta_{10} \mathrm{Z}_{i t} * \mathrm{P}_{i t}+\mathrm{CONTROLS}_{i t} .
\end{aligned}
$$

\section{Descriptive statistics}

We present the distribution of the main variables in Figure 1. 12 percent of the respondents are "not too happy," 56 percent are "pretty happy," and 32 percent are "very happy."5 Perceived relative income seems to have a normal distribution. 2 percent of the sample think they are "far above average," and 19 percent think they are "above average." 51 percent think they are "average," and 24 percent are "below average," but only 1 percent think they are "far below average" income. Concerning status, 5 percent of the sample thinks they are the "lower class," 46 percent "working class," 46 percent "middle class," and only 3 percent think they are "upper class." Perceptions about dwelling varies as well. With respect to dwellings in the neighborhood, only 1 percent think their dwelling is "far above

\footnotetext{
${ }^{5}$ People tend to choose the item in the middle in the categorical questions and this may bias our results, therefore we also consider using happiness available as 4 and 7 categories (which are available only by a small fraction of the sample) in the robustness section.
} 
average," 15 percent "above average," 71 percent "average," 11 percent "below average," and 2 percent "far below average." Perceptions with respect to dwellings in the city appears to be normally distributed. 3 percent far "above average," 19 percent "above average," 56 percent "average," 19 percent "below average," and 3 percent "far below average."

Figure 2 illustrates graphically whether the part of happiness which can not be explained by the demographic variables is related to perceptions by plotting the residuals from a regression of happiness on demographic variables against perceptions. Figure 2 shows a clear pattern of people with higher perceptions reporting higher happiness. We then examine the evolution of the happiness and perceptions about relative income in the United States since 1972. We calculate yearly averages of happiness and perceived relative income in the GSS (25 observations) and plot those against time in Figure 3. There is large variation both in happiness and perceived relative income which partly lines up with U.S. recessions although we will not study that issue in detail. There was a sharp increase in happiness after 1970 for a couple of years and then happiness declined a little bit but increased again until 1980. Overall, happiness appears to go up from 1970s to 1980s in the GSS. However, happiness decreased from 1980 until mid 1980s and then went up until 1990s. The evolution of happiness between 1990 and 2000 is similar to the one between 1980 and 1990. The lowest levels of happiness were experienced around 1985 and 1995 and the highest was experienced around 1988. Around 1982, we observe a huge decline in perceptions about relative income with a sharp increase in the following years. Perceptions about relative income are highest around 1975 and lowest around 1982. Overall, perceptions about relative income and happiness appear to move hand to hand most of the time.

Table 1 considers perceived income rankings and happiness and we observe a positive relationship between perceptions of relative income and happiness. Table 2 reveals a positive relationship between perceptions about one's social class and happiness. Perceived relative income is, not surprisingly, closely related to actual relative income as can be seen from Table 3. Interestingly, a large number of individuals perceive themselves to have average income, almost independently of their actual income; for example, 44 percent of individuals with actual income far below average consider themselves to have "average" income while 49 percent of individuals with actual income far above average consider themselves to have "average" income.

Table 4 shows that the correlation between actual and perceived relative income is posi- 
tive at 0.48 . The correlation between actual income and reference group income is 0.67 and the correlation between perceived relative income and reference group income is quite low at 0.36 . The lack of perfect correlation allows us to estimate the impact of perceived and actual income ranking simultaneously and evaluate if both matter for happiness and which one is more important. Perceived social status is correlated with perceived relative income at 0.37 but much less so with reference group income at 0.26 . Perceived social status is positively correlated with actual social status but this correlation is also low at 0.27 . Household income is positively correlated with perceived social status with a correlation of 0.33 . Perceptions about relative income during childhood, as expected, have the highest correlation with current perceptions about relative income but this number is only 0.19 .

\section{$6 \quad$ Empirical results}

Table 5 presents OLS estimates and t-statistics for our baseline specification. We find that income positively relates to happiness with a t-statistic of almost $15{ }^{6}$ However, reference group income has a significant negative influence on happiness. One point increase in $\ln$ reference group income leads to a 0.015 point reduction in happiness. Dwelling ownership correlates happiness as renters are 0.024 points less happy than house owners. Employment status also significantly affects happiness (the omitted category is the working category); however, we do not find any significant impact of working hours on happiness. Unemployed are 0.139 points "less happy than employed individuals and people out of the labor force are happier than those who are working. $]^{7}$ Females are 0.045 points happier than males consistent with most studies around the world.

Happiness is non-linear in age -increasing at early ages and then decreasing but at a decreasing rate and blacks are very significantly less happy than whites. We see a significant effect of education on happiness with one more year of education associated with a 0.011 points increase in happiness. Household size is negatively correlated with happiness while marital status is a very strong predictor of happiness according to Table 5 (the omitted category is not being married). Married are 0.249 points happier than nonmarried.

\footnotetext{
${ }^{6}$ We use real income in all our regressions - Winkelmann et al. (2007b) show that there is no money illusion with respect to individual satisfaction.

${ }^{7}$ Winkelmann et al. (2007a) show that well-being from working in ones chosen job may be higher rather than from in any random job.
} 
Concerning religious preferences, Protestants, Orthodox-Christians, and Christians are happier than Catholics (omitted category); however, Jewish, Buddhists, non religious, and adherents of Native American religions are less happy than Catholics. Living in a big city is correlated with less happiness and a one point increase in ln local population leads to a 0.008 point decrease in happiness.

We estimate the baseline regression separately for non-married and married. Income comparisons are more important for married but the positive influence of income on happiness is larger for nonmarried and dwelling ownership appears to be more important for nonmarried as well. Being unemployed, or not in the labor force, affects happiness more for married while it appears that the female-male happiness gap decreases with marriage. Married blacks are much less happy than single blacks. The influence of education on happiness is two times higher for nonmarried while the influence of religion on happiness is higher for married. For instance, among nonmarried, non-religious are 0.049 points less happy than Catholics and this number increases to 0.088 for married. The negative influence of city size on happiness for the married sample is similar to the one for the nonmarried sample. Lastly, happiness responses are explained better by the independent variables for nonmarried as suggested by a higher adjusted R-squared.

Tables 6 and 7 focus on our main task; namely, estimating the contributions of income, relative income, and perceptions to happiness. In order to hedge against spurious conclusions due to potentially erroneous assumptions of linearity, we present the results from two specifications - one where income is measured as a "continuous" variable (in Tables 6 and 7) and one where we use dummy variables for income categories and perceptions (Table 8). In these tables we, for brevity, only display the main coefficients of interest.

We performed a series of regressions in order to identify the reference group that has the strongest effect on happiness. We do not report the details but our results indicate that individuals compare themselves to individuals from their own cohort who work in the same occupation and live in the same region. By doing a specification search like this we may overestimate the impact of relative income due to "data mining," although we may also underestimate the effect of relative income because we do not really know which groups individuals compare themselves to. If people, as argued by Gilbert and Trower (1990), choose whom to compare themselves to, it may be the case that they tend to compare themselves to individuals that are systematically better or worse off than themselves. If such is the case, 
then perceived relative income may be a "more correct" measure of relative income than our measured relative income in a technical sense. However, it is very hard to empirically separate the case where individuals choose their comparison group from the case where individuals form imperfect perceptions. We examined if individuals know about other people's income with a lag by checking if "reference group income," defined as the income of the comparison group one year earlier, is more significant than reference group income calculated from the current income of the comparison group. We found no evidence of such an information lag and do not tabulate the results.

We display the coefficients to actual income, reference group income, perceived relative income, and social status while suppressing those of demographic variables. In Table 6, we use ln values of our main variables and both actual income and reference group income are significant. However, the coefficient to perceived relative income is four times that of the coefficient to actual income and 12 times that of reference group income. This coefficient is estimated with an extremely high level of significance with a t-statistic of 27 . In the second column, we include occupational prestige but it is not significant. In the third column, we include perceived social class which is a strongly significant predictor of happiness with a t-statistic of 11.4 The inclusion of this variable lowers the significance of perceived relative income, as one might expect, but this reduction is quite small. It appears that perceived relative income and perceived social class have separate strong impacts on happiness.

In Table 7, we investigate the role of perceptions about own dwelling. We use two variables: perceptions with respect to other dwellings in the city and perception with respect to other dwellings in the neighborhood. The reference group is much more clearly stated for these variables. Perceived dwelling status relative to other dwellings in the city is significantly and positively correlated with happiness after controlling for dwelling ownership and dwelling type. In the second column, we include perceived dwelling status relative to other dwellings in the neighborhood and find a larger, more significant, coefficient. This result clearly supports Luttmer's (2005) notion of "neighbors as negatives" in the sense that observable well-being of neighbors can lower happiness.

In Table 8, we enter income, status, and perception variables as dummy variables. Such a specification does not impose the restriction that the change in happiness when moving from

\footnotetext{
${ }^{8}$ We still include occupational prestige in column 3 and in all regressions where perceived social class enters as a correlate of happiness in the rest of the paper. However, we do not report the coefficients since they are not significant as one may expect from the results in the second column of Table 6 .
} 
one level of, say, income to a higher level of ln income is the same for all levels of income as does the log-linear specification in the previous table. We find that all categories of income are significant in explaining happiness. Reference group income has a significant and negative effect only for the "far above average" category while perceived relative income has a positive effect with extremely high significance for the "average" and "above average" categories ("far below average" is the omitted category). Perceived social class is significant at high levels of significance for all categories (compared to the left-out category "far below average") with t-values around 13. Overall, these results provide clear evidence that people's perceptions of income and status are highly correlated with happiness. Concerning perceptions about dwelling, perceptions relative to city dwellings is significant for all categories except "below average." Perceptions relative to dwellings in the neighborhood is significant for all categories in explaining happiness and is a stronger predictor than the former as found above.

Next, in Table 9, we investigate the role of selection. We consider three sub-samples: people living in the same city since childhood, people living in the same state but in a different city, and people living in a different state. The results show that perceptions matter for all three categories. Reference group income and perceived social class has a stronger effect on happiness for those who have moved; however, the income and happiness correlation is higher for people who never moved to another city or state. Perceived relative income is highest in significance and in size of the coefficient for those who remain in their childhood city. Dwelling perceptions clearly matter more for those not moving, while it appears that dwelling perceptions do not matter for happiness once people move to another city. In the bottom row, we use nominal values of income and find results very similar to what we found using real values.

In Table 10, we add interaction terms with our perceived relative measures (income, status, dwelling) and find that perceptions about relative income are more important for low income individuals, females, and conservatives. Perceived social class matters more for conservatives. Perceptions about own dwelling are more important for happiness of married, middle income individuals, males, and conservatives while perceptions matter less for people with higher intelligence as measured by the ability to guess words. Inequality aversion lessens the influence of perceived income and social class but strengthens the impact of dwelling perceptions. Hours of TV watched interact positively with dwelling perceptions.9 When we

\footnotetext{
${ }^{9}$ We also tried interactions with being self-employed (versus being an employee). We did not find any
} 
interact our relative perception measures (income, status, dwelling) with interpersonal trust, we observe that perceptions matter more for less trusting people. Interestingly, trust matters most for perceived relative income according to both size and significance of the interaction. Indeed, the coefficient on the interaction terms between trust and perceived relative income is three times higher compared with the interaction between trust and perceived dwelling status (neighborhood and city). Trust matters more for perceived social class than for perceived dwelling status.

\section{Conclusion}

High income is correlated with higher levels of happiness but high reference group income is negatively related to happiness. However, even if income is low in both absolute and relative terms, happiness is within reach as long a perceived social status or perceived relative income is high. Perceptions about own dwelling relative to other dwellings are also important for the well-being reinforcing the conclusion that happiness strongly correlates with perceptions.

significant results when we used our perception variables as continuous variables. However, when we used perceptions as categorical variables, we found significant interaction effects only for perceived relative income. 


\section{References}

[1] Blanchflower, D.G.,\& Oswald, A.J. (2000a). The Rising Well-Being Of the Young. NBER Working Paper No. 6102.

[2] Blanchflower, D.G.,\& Oswald, A.J. (2000b). Well-Being Over Time In Britain and the U.S.A. NBER Working Paper No. 7787.

[3] Clark, A.E.,\& Oswald, A.J. (1994). Unhappiness and Unemployment. Economic Journal 104, 648-659.

[4] Clark, A.E., Frijters, P.,\& Shields, M.A. (2008). Relative Income, Happiness and Utility: An Explanation For the Easterlin Paradox and Other Puzzles. Journal of Economic Literature 46, 95-144.

[5] Clark, A.E., Kristensen, N., \& Westergård-Nielsen, N. (2009). Economic Satisfaction and Income Rank In Small Neighbourhoods. Journal of the European Economic Association 7, 519-527.

[6] Clark, A.E., Oswald, A.J. (1996). Satisfaction and Comparison Income. Journal of Public Economics 61, 359-381.

[7] Clark, Andrew E.,\& Senik, C. (2010). Who Compares To Whom? The Anatomy Of Income Comparisons In Europe. The Economic Journal 120, 573-594.

[8] DiTella, R., Haisken-De-New, J., \& MacCulloch, R. (2010). Happiness Adaptation To Income and To Status In An Individual Panel. Journal of Economic Behavior and Organization forthcoming.

[9] Duesenberry, J. (1949). Income, Savings and the Theory Of Consumer Behaviour. Cambridge, Mass: Harvard University Press.

[10] Easterlin, R.A. (1963). Towards A Socio-economic Theory Of Fertility: A Survey Of Recent Research On Economic Factors In American Fertility. In S.J. Behrman, L. Corsa Jr., R.Freedman (Eds.) Fertility and Family Planning: A World View 127-156. Ann Arbor: University of Michigan Press. 
[11] Easterlin, R.A. (1973). Relative Economic Status and the American Fertility Swing. In E.B. Sheldon (Ed.). Family Economic Behavior: Problems and Prospects, Philadelphia: J.B. Lippincott for Institute of Life Insurance.

[12] Freedman, D.S. (1963). The Relation Of Economic Status On Fertility. American Economic Review 53, 414-426.

[13] Frey, S.B., \& Stutzer, A. (2002). What Can Economists Learn From Happiness Research. Journal of Economic Literature 40, 402-435.

[14] Frijters, P., \& Ferrer-i-Carbonell, A. (2003). How Important Is Methodology For the Estimates Of the Determinants Of Happiness? The Economic Journal 114, 641-659.

[15] Gilbert, P., \& Trower, P. (1990). The Evolution and Manifestation Of Social Anxiety. In R.W. Crozier (Ed.). Shyness and Embarrassment: Perspectives from Social Psychology, 144-177. New York: Cambridge University Press.

[16] Graham, C. (2004). Can Happiness Research Contribute to Development Economics? Washington DC: The Brookings Institution.

[17] Luttmer, E. (2005). Neighbors As Negatives: Relative Earnings and Well-Being. Quarterly Journal of Economics 120, 963-1002.

[18] Moller, V. (1989). Can’t Get No Satisfaction. Indicator South Africa 7, 43-46.

[19] Oswald, J.A. (1997). Happiness and Economic Performance. Economic Journal 107, 1815-1831.

[20] Rablen, M.D. (2008). Relativity, Rank and the Utility Of Income. The Economic Journal 118, 801-821.

[21] Senik, C. (2009). Direct Evidence On Income Comparison and Their Welfare Effects. Journal of Economic Behavior and Organization forthcoming.

[22] Van Praag, B.M.S., \& Kapteyn, A. (1973). Wat Is Ons Inkomen Ons Waard? (How Do We Value Our Income?) Economisch Statistische Berichten 58, 360-382.

[23] Wachter, M.L. (1972). A Labor Supply Model For Secondary Workers. The Review of Economics and Statistics 54, 141-151. 
[24] Wachter, M.L. (1974). A New Approach To the Equilibrium Labor Force. Economica $41,35-51$.

[25] Winkelmann, R., Luechinger, S., Stutzer, A. (2007a). The Happiness Gains From Sorting and Matching In the Labor Market. University of Zurich Working Paper.

[26] Winkelmann, R., Boes, S. \& Lipp, M. (2007b). Money Illusion Under Test. Economics Letters 94, 332-337.

[27] Winkelmann, R., Boes, S. \& Staub, K. (2007c). The Hidden Cost Of Parental Income: Why Less May Be More. University of Zurich Working Paper.

[28] Wright, S.C. (1985). Health Satisfaction: A Detailed Test Of the Multiple Discrepancies Theory Model. Social Indicators Research 17, 299-313. 


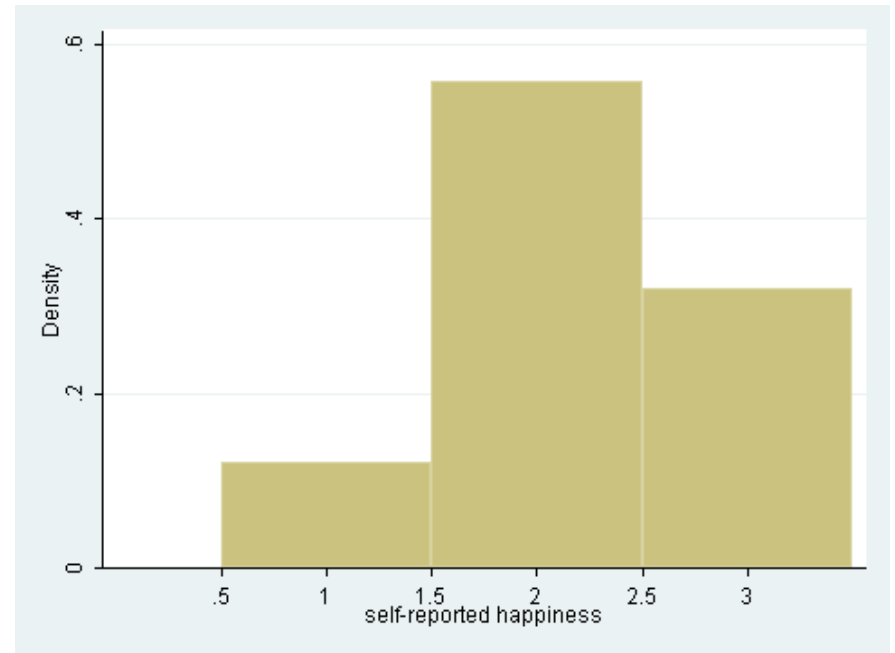

(a)

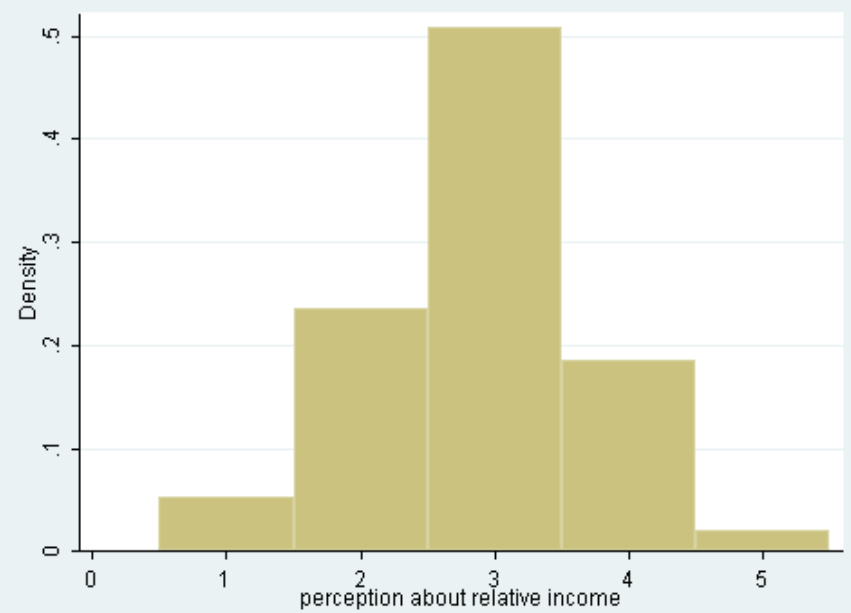

(b)

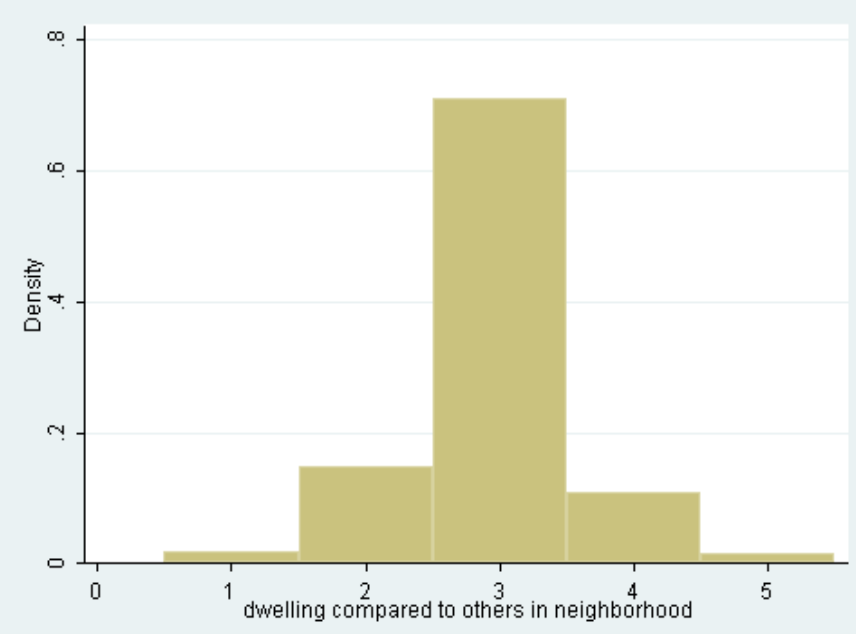

(d)

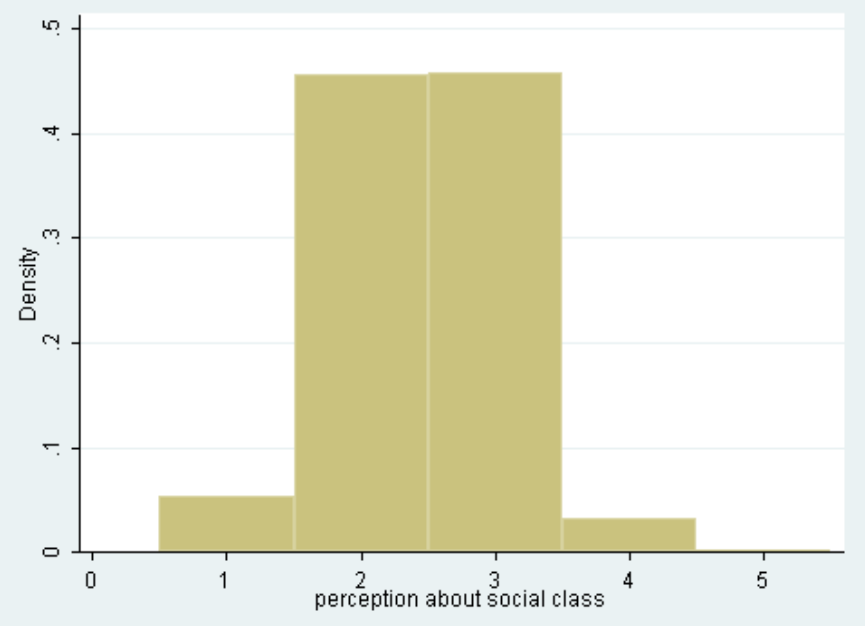

(c)

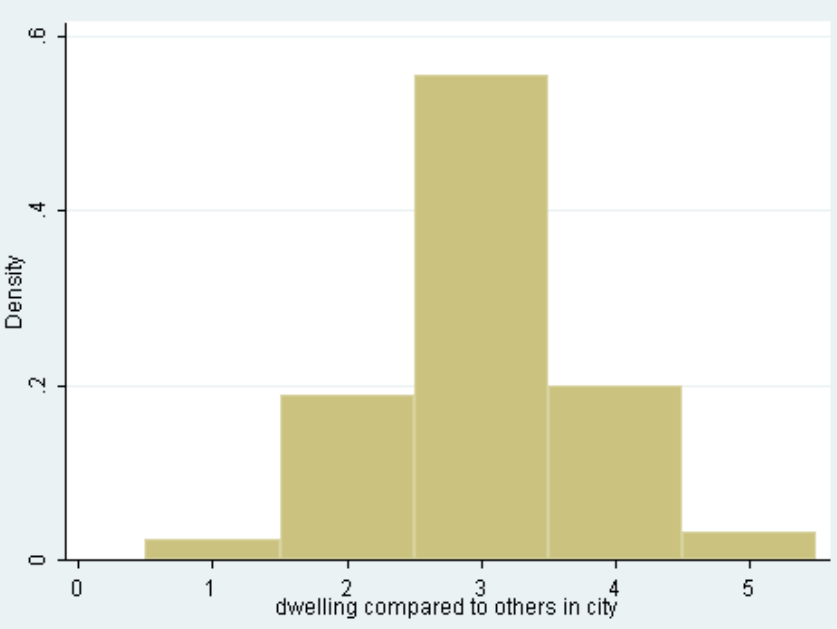

(e)

Figure 1: Distribution of the main variables (whole sample) 


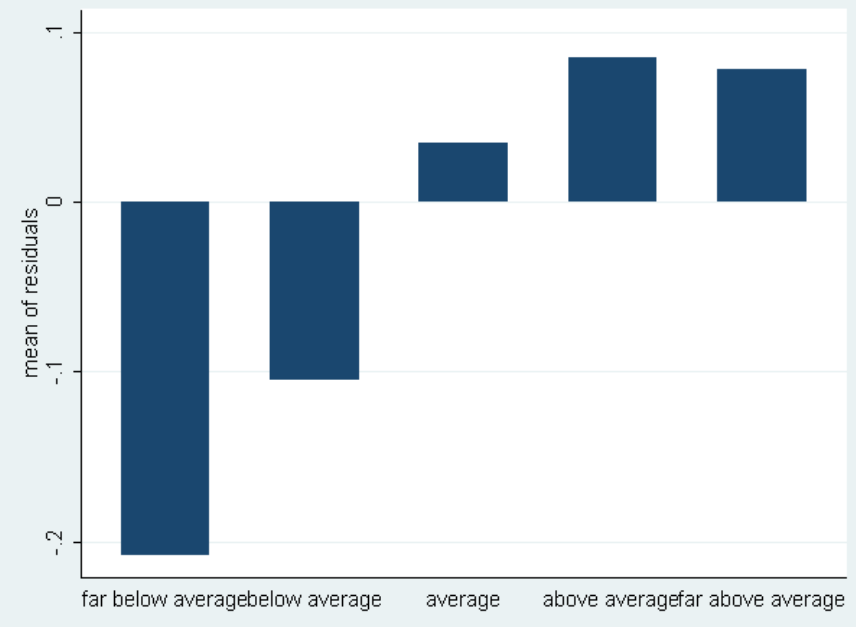

(a) perceived relative income

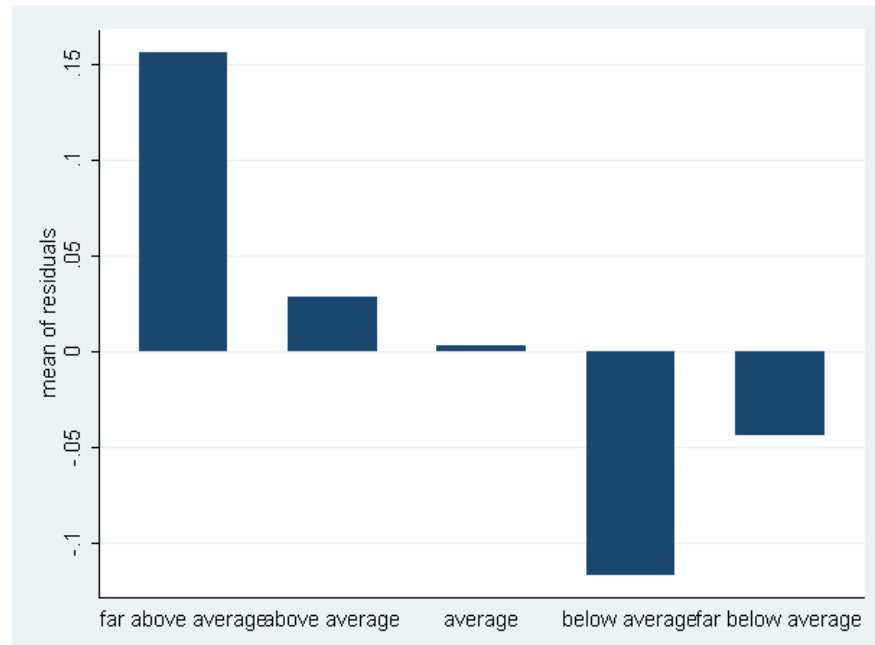

(c) perceived dwelling status/neighborhood

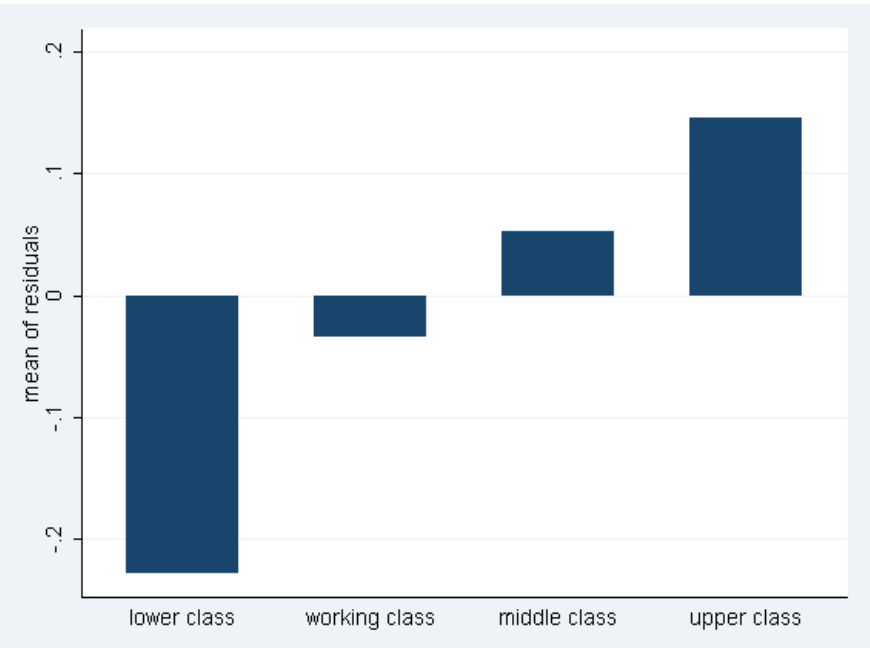

(b) perceived social class

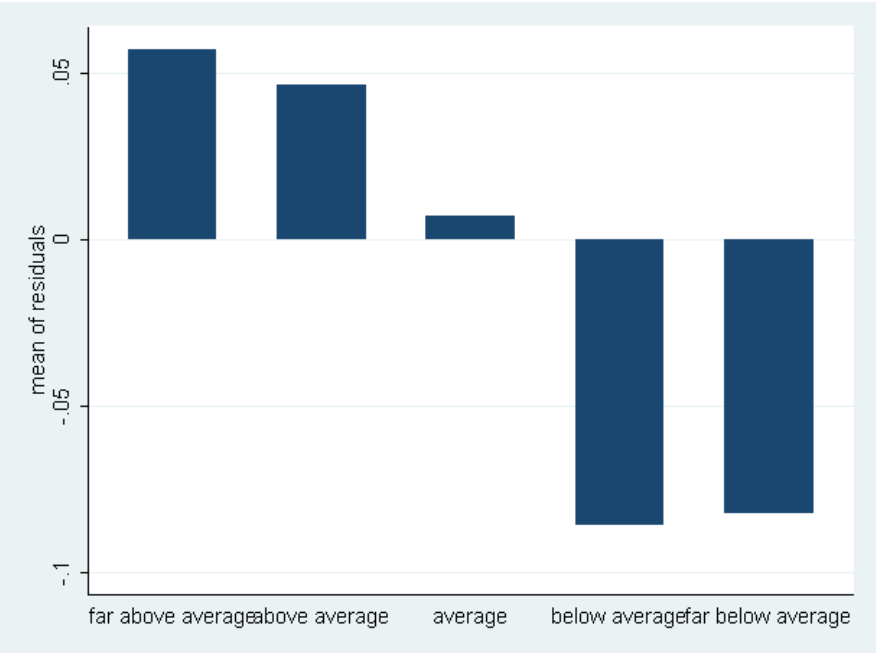

(d) perceived dwelling status/city

Figure 2: Residual happiness by main variables (whole sample) 


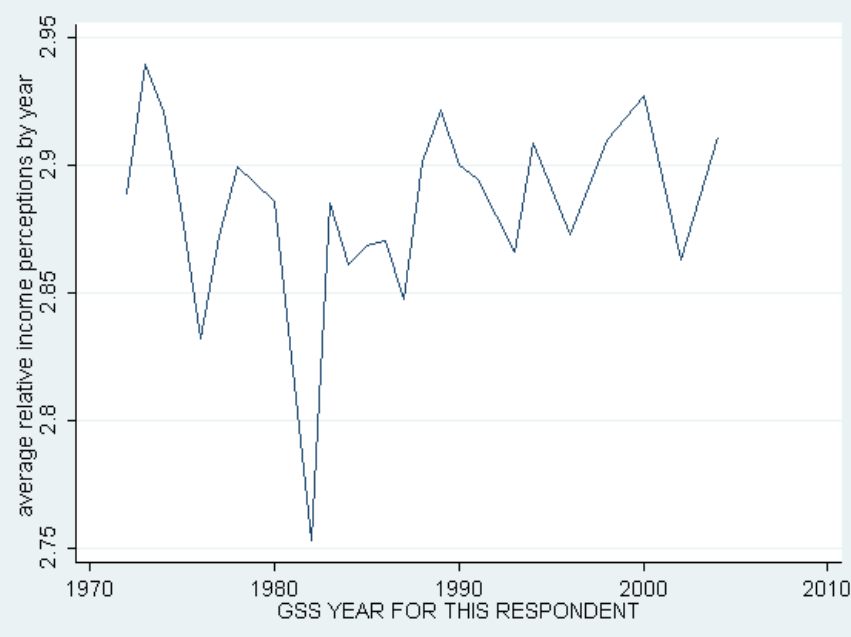

(a) time series of perceived relative income

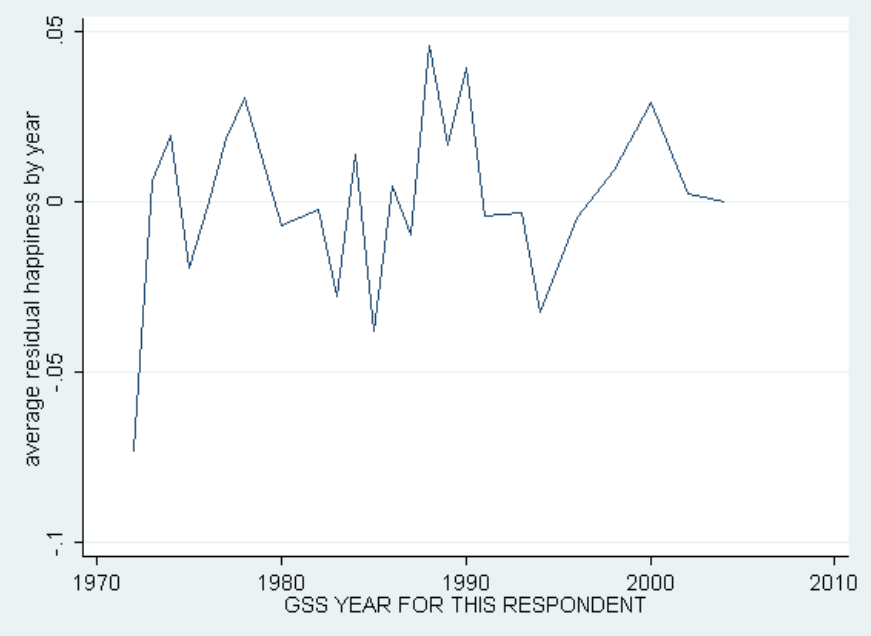

(b) time series of happiness

Figure 3: Yearly averages 
Table 1: Descriptive statistics: Perceptions about relative income and happiness

\begin{tabular}{lccrr}
\hline \hline & & & & \\
happiness: & low & middle & high & total \\
\hline & & & & \\
perceived relative income: & & & & \\
far below average & 32 & 49 & 19 & 2222 \\
below average & 19 & 58 & 23 & 10090 \\
average & 10 & 57 & 33 & 21821 \\
above average & 6 & 52 & 42 & 7920 \\
far above average & 11 & 46 & 43 & 834 \\
\hline \hline
\end{tabular}

Notes: This table shows happiness of individuals by perceptions about relative income. Perceived relative income is a categorical variable taking values $1-5$.

Table 2: Descriptive statistics: Perceptions about social class and happiness

\begin{tabular}{lcccr}
\hline \hline happiness: & low & middle & high & total \\
\hline & & & & \\
perceived social class: & & & & \\
lower class & 33 & 51 & 16 & 2205 \\
working class & 13 & 60 & 27 & 19067 \\
middle class & 9 & 54 & 37 & 18923 \\
upper class & 10 & 43 & 47 & 1344 \\
\hline \hline
\end{tabular}

Notes: This table shows happiness of individuals by perceptions about social class. Perceived social class is a categorical variable taking values $1-4$. 


\section{Table 3: Descriptive statistics: Relation between income and perceptions about relative income}

\begin{tabular}{lccccc}
\hline \hline perceived relative income: & $\begin{array}{c}\text { far below } \\
\text { average }\end{array}$ & $\begin{array}{c}\text { below } \\
\text { average }\end{array}$ & average & $\begin{array}{c}\text { above } \\
\text { average }\end{array}$ & $\begin{array}{c}\text { far above } \\
\text { average }\end{array}$ \\
\hline income: & & & & & \\
far below average & 9 & 41 & 44 & 4 & 2 \\
below average & 4 & 27 & 59 & 10 & 0 \\
average & 3 & 5 & 52 & 38 & 2 \\
above average & 1 & 4 & 40 & 48 & 7 \\
far above average & 2 & 19 & 49 & 28 & 2 \\
\hline \hline
\end{tabular}

Notes: Numbers are row percentages. Income is recoded into five categories from the original data containing 13 categories. Perceived relative income is 5 categories: "far below average," "below average," "average," "above average," and "far above average."

\section{Table 4: Correlation matrix: Main variables}

\begin{tabular}{|c|c|c|c|c|c|c|}
\hline & $\begin{array}{l}\text { household } \\
\text { income }\end{array}$ & $\begin{array}{l}\text { reference } \\
\text { group } \\
\text { income }\end{array}$ & $\begin{array}{l}\text { perceived } \\
\text { relative } \\
\text { income }\end{array}$ & $\begin{array}{l}\text { occupational } \\
\text { prestige }\end{array}$ & $\begin{array}{l}\text { perceived } \\
\text { social } \\
\text { class } \\
\text { when } 16 \\
\text { years old }\end{array}$ & $\begin{array}{l}\text { perceived } \\
\text { relative } \\
\text { income }\end{array}$ \\
\hline household income & 1.00 & & & & & \\
\hline reference group income & 0.67 & 1.00 & & & & \\
\hline perceived relative income & 0.48 & 0.36 & 1.00 & & & \\
\hline occupational prestige & 0.34 & 0.38 & 0.23 & 1.00 & & \\
\hline perceived social class & 0.33 & 0.26 & 0.37 & 0.27 & 1.00 & \\
\hline $\begin{array}{l}\text { perceived relative income } \\
\text { when } 16 \text { years old }\end{array}$ & 0.16 & 0.14 & 0.19 & 0.16 & 0.18 & 1.00 \\
\hline
\end{tabular}

Notes: All variables are in ln. Perceived relative income is 5 categories: "far below average," "below average," "average," "above average," and "far above average." Perceived social class is 4 categories: "lower class," "working class," "middle class," and "upper class." Occupational prestige takes values 0-100. 


\title{
Table 5: Baseline regressions
}

\author{
Dependent Variable: Self-reported Happiness
}

\begin{tabular}{|c|c|c|c|}
\hline & $\begin{array}{l}\text { OLS } \\
\quad(1)\end{array}$ & $(2)$ & $(3)$ \\
\hline & baseline & married & nonmarried \\
\hline ln reference group income & $-0.015(2.1)$ & $-0.027(2.5)$ & $-0.011(1.7)$ \\
\hline ln household income & $0.077(15.1)$ & $0.108(11.3)$ & $0.060(12.2)$ \\
\hline rent dwelling & $-0.024(2.4)$ & $-0.021(1.4)$ & $-0.032(2.8)$ \\
\hline ln weekly working hours & $-0.009(0.7)$ & $-0.012(1.0)$ & $0.014(0.8)$ \\
\hline unemployed & $-0.139(4.7)$ & $-0.171(3.6)$ & $-0.108(4.2)$ \\
\hline not in the labor force & $0.055(5.1)$ & $0.073(2.9)$ & $0.032(1.6)$ \\
\hline female & $0.045(5.9)$ & $0.023(2.9)$ & $0.046(3.9)$ \\
\hline age & $-0.011(6.8)$ & $-0.007(3.9)$ & $-0.017(13.3)$ \\
\hline age-squared/100 & $0.012(7.9)$ & $0.008(4.4)$ & $0.002(12.7)$ \\
\hline black & $-0.119(16.4)$ & $-0.153(14.3)$ & $-0.087(10.3)$ \\
\hline not white or black & $-0.021(1.1)$ & $-0.009(0.4)$ & $-0.042(2.9)$ \\
\hline years of education & $0.011(10.6)$ & $0.008(4.1)$ & $0.016(16.1)$ \\
\hline $\begin{array}{l}\text { In household size } \\
\text { not married (omitted) }\end{array}$ & $-0.014(2.4)$ & $-0.048(2.4)$ & $-0.002(0.2)$ \\
\hline married & $0.249(31.5)$ & & \\
\hline Catholic (omitted) & & & \\
\hline Protestant & $0.025(2.6)$ & $0.028(2.5)$ & $0.016(1.5)$ \\
\hline Jewish & $-0.083(3.2)$ & $-0.052(1.6)$ & $-0.129(4.0)$ \\
\hline No religion & $-0.064(7.9)$ & $-0.088(4.2)$ & $-0.049(4.4)$ \\
\hline Other religions & $-0.026(1.2)$ & $-0.021(1.0)$ & $-0.037(1.1)$ \\
\hline Buddhist & $-0.121(2.6)$ & $-0.054(0.4)$ & $-0.149(1.8)$ \\
\hline Hindu & $-0.049(0.7)$ & $0.002(0.1)$ & $-0.153(1.9)$ \\
\hline Other eastern religions & $-0.061(0.2)$ & $-0.069(0.2)$ & $-0.087(0.3)$ \\
\hline Muslim & $0.157(1.3)$ & $0.188(1.2)$ & $0.082(0.6)$ \\
\hline Orthodox-Christian & $0.182(2.5)$ & $0.227(2.7)$ & $0.089(1.1)$ \\
\hline Christian & $0.075(1.5)$ & $0.133(2.7)$ & $0.015(0.3)$ \\
\hline Native American religions & $-0.287(5.8)$ & $-0.652(1.9)$ & $-0.171(1.1)$ \\
\hline Inter-nondenominational & $0.043(0.9)$ & $0.060(0.6)$ & $0.017(0.2)$ \\
\hline ln place population & $-0.008(7.7)$ & $-0.007(4.5)$ & $-0.009(5.3)$ \\
\hline region fixed effects & Yes & Yes & Yes \\
\hline year fixed effects & Yes & Yes & Yes \\
\hline occupation fixed effects & Yes & Yes & Yes \\
\hline industry fixed effects & Yes & Yes & Yes \\
\hline Adjusted R-squared & 0.0917 & 0.0428 & 0.0516 \\
\hline Number of observations & 43317 & 24249 & 19062 \\
\hline
\end{tabular}

Notes: We estimate Equation 1 using OLS for the whole sample in column (1). We estimate self-reported happiness of an individual $i$ at time $t$ as a function of his/her $\ln$ reference group income and ln household income together with the following controls variables: dwelling ownership, ln weekly working hours, labor force status, sex, age, age square, race, years of education, ln household size, marital status, religion, In population of the place of residence, region fixed effects, year fixed effects, occupation fixed effects, and industry fixed effects. In reference group income is the ln average income of people who live in the same region, work in the same occupation category (1-digit) and are at the same age with the respondent. In column (2), we estimate the same equation only for the married sample, and in column (3), the estimation is done only for the nonmarried sample. Self-reported happiness is measured on a scale 1-3 which corresponds to: "very happy," "pretty happy," and "not too happy." t-statistics in absolute values are reported in parentheses. Robust standard errors are used. 


\section{Table 6: The role of perceptions about relative income and status}

Dependent Variable: Self-reported Happiness

\begin{tabular}{|c|c|c|c|c|c|c|}
\hline & \multicolumn{2}{|c|}{$\begin{array}{l}\text { OLS } \\
(1)\end{array}$} & \multicolumn{2}{|c|}{$(2)$} & \multicolumn{2}{|c|}{$(3)$} \\
\hline main variables $\downarrow \downarrow$ & coeff. & t-stat. & coeff. & t-stat. & coeff. & t-stat. \\
\hline ln reference group income & -0.021 & 2.7 & -0.023 & 2.9 & -0.023 & 3.0 \\
\hline ln household income & 0.070 & 11.9 & 0.070 & 11.7 & 0.063 & 11.3 \\
\hline ln perceived relative income & 0.258 & 27.2 & 0.256 & 28.6 & 0.217 & 21.4 \\
\hline ln occupational prestige & & & 0.012 & 0.7 & 0.010 & 0.6 \\
\hline ln perceived social class & & & & & 0.189 & 11.4 \\
\hline Adjusted R-squared & \multicolumn{2}{|c|}{0.0802} & \multicolumn{2}{|c|}{0.0825} & \multicolumn{2}{|c|}{0.0882} \\
\hline Number of observations & \multicolumn{2}{|c|}{43317} & \multicolumn{2}{|c|}{43317} & \multicolumn{2}{|c|}{43317} \\
\hline
\end{tabular}

Notes: OLS regressions. In column (1), we estimate Equation 2 and present the coefficients for the main variables of interest. We estimate self-reported happiness of an individual $i$ at time $t$ as a function of his/her $\ln$ perceived relative income, ln reference group income and ln household income together with the same control variables used in Table 5, column 1. Perceived relative income is the answer to the question, "Compared with American families in general, would you say your family income is far below average, below average, average, below average, or far above average?" Perceived relative income takes the values 1-5 and treated as a continuous variable in this estimation. In column (2), we estimate self-reported happiness of an individual $i$ at time $t$ as a function of his/her ln occupational prestige, ln perceived relative income, ln reference group income and ln household income together with the same control variables used in Table 5, column 1. Occupational prestige takes values 0-100 where higher values correspond to higher occupational prestige. In column (3), we estimate self-reported happiness of an individual $i$ at time $t$ as a function of his/her $\ln$ perceived social class, ln occupational prestige, ln perceived relative income, ln reference group income and $\ln$ household income together with the same control variables used in Table 5, column 1. Perceived social status is the answer to the question, "If you were asked to one of four names for your social class, which would you say you belong in? The lower class, the working class, the middle class, or the upper class?" It takes values $1-4$ and is treated as a continuous variable in the estimation. Self-reported happiness is measured on a scale 1-3 which corresponds to: "very happy," "pretty happy," and "not too happy." t-statistics are reported in absolute values. Robust standard errors are used. 


\section{Table 7: Comparing dwelling to others in the neighborhood and the city}

Dependent Variable: Self-reported Happiness

\begin{tabular}{|c|c|c|c|c|}
\hline OLS & \multicolumn{2}{|c|}{ (1) } & \multicolumn{2}{|c|}{$(2)$} \\
\hline main variables $\downarrow$ & coeff. & t-stat. & coeff. & t-stat. \\
\hline ln reference group income & -0.024 & 2.9 & -0.022 & 2.8 \\
\hline ln household income & 0.062 & 11.6 & 0.064 & 12.6 \\
\hline ln perceived relative income & 0.216 & 20.9 & 0.217 & 20.1 \\
\hline ln perceived social class & 0.189 & 11.1 & 0.193 & 11.5 \\
\hline ln perceived dwelling status (city) & 0.082 & 2.1 & & \\
\hline ln perceived dwelling status (neighborhood) & \multirow{2}{*}{\multicolumn{2}{|c|}{ Yes }} & 0.118 & 4.2 \\
\hline dwelling type dummies & & & \multicolumn{2}{|c|}{ Yes } \\
\hline Adjusted R-squared & \multicolumn{2}{|c|}{0.0851} & \multicolumn{2}{|c|}{0.0852} \\
\hline Number of observations & \multicolumn{2}{|c|}{43317} & \multicolumn{2}{|c|}{43317} \\
\hline
\end{tabular}

Notes: OLS regressions. In column (1), we estimate Equation 5 and present the coefficients only for the main variables. We estimate self-reported happiness of an individual $i$ at time $t$ as a function of his/her ln perceived dwelling status with respect to other dwellings in his/her city, type of his/her dwelling, ln perceived social class, ln occupational prestige, ln perceived relative income, ln reference group income and ln household income together with the same control variables used in Table 5, column 1. Perceived dwelling status (city) is the answer to the question, "Compared to apartments/houses in the city, would you say the house/apartment was..." and the answer is a categorical variable which is "far below average" (1), "below average" (2), "average" (3), "above average" (4), "far above average" (5), and no answer (missing), not applicable (missing). It takes values 1-5 and is treated as a continuous variable in the estimation. In column (2), we estimate Equation 6 using and present the coefficients only for the main variables of interest. We estimate self-reported happiness of an individual $i$ at time $t$ as a function of his/her $\ln$ perceived dwelling status with respect to other dwellings in his/her neighborhood, type of his/her dwelling, ln perceived social class, ln occupational prestige, ln perceived relative income, ln reference group income and ln household income together with the same control variables used in Table 5, column 1. Dwelling type is the same as explained above. Perceived dwelling status (neighborhood) is the answer to the question, "Compared to apartments/houses in the neighborhood, would you say the house/apartment was..." and the answer is a categorical variable which is; "far below average" (1), "below average" (2), "average" (3), "above average" (4), "far above average" (5), and no answer (missing), not applicable (missing). It takes values 1-5 and is treated as a continuous variable in the estimation. Self-reported happiness is measured on a scale 1-3 which corresponds to: "very happy," "pretty happy," and "not too happy." t-statistics are reported in absolute values. Robust standard errors are used. 


\section{Table 8: Nonlinearities in perceptions}

Dependent Variable: Self-reported Happiness

\begin{tabular}{|c|c|c|c|c|c|}
\hline \multirow{3}{*}{$\begin{array}{l}\text { main variables } \downarrow \\
\text { reference group income: }\end{array}$} & OLS & \multicolumn{2}{|c|}{$(1)$} & \multicolumn{2}{|c|}{$(2)$} \\
\hline & & coeff. & t-stat. & coeff. & t-stat. \\
\hline & (omitted) far below average & & & & \\
\hline & $\begin{array}{r}\text { below average } \\
\text { average }\end{array}$ & $\begin{array}{l}-0.002 \\
-0.009\end{array}$ & $\begin{array}{l}0.3 \\
0.8\end{array}$ & $\begin{array}{l}-0.002 \\
-0.009\end{array}$ & $\begin{array}{l}0.4 \\
0.7\end{array}$ \\
\hline & above average & -0.004 & 0.4 & -0.004 & 0.5 \\
\hline & far above average & -0.014 & 2.1 & -0.014 & 2.2 \\
\hline \multirow[t]{5}{*}{ household income: } & (omitted) far below average & & & & \\
\hline & below average & 0.017 & 1.8 & 0.018 & 1.8 \\
\hline & average & 0.045 & 3.6 & 0.045 & 3.7 \\
\hline & above average & 0.045 & 3.3 & 0.045 & 3.3 \\
\hline & far above average & 0.085 & 6.7 & 0.085 & 6.9 \\
\hline \multirow[t]{5}{*}{ perceived relative income: } & (omitted) far below average & & & & \\
\hline & below average & 0.090 & 4.1 & 0.090 & 4.0 \\
\hline & average & 0.212 & 13.5 & 0.212 & 13.8 \\
\hline & above average & 0.249 & 13.7 & 0.249 & 13.8 \\
\hline & far above average & 0.227 & 4.9 & 0.227 & 4.9 \\
\hline \multirow[t]{4}{*}{ perceived social class: } & (omitted) below average & & & & \\
\hline & average & 0.143 & 12.9 & 0.144 & 13.4 \\
\hline & above average & 0.210 & 13.7 & 0.210 & 14.0 \\
\hline & far above average & 0.306 & 11.6 & 0.306 & 11.8 \\
\hline \multirow[t]{5}{*}{ perceived dwelling status (city): } & (omitted) far below average & & & & \\
\hline & below average & 0.040 & 0.8 & & \\
\hline & average & 0.063 & 2.0 & & \\
\hline & above average & 0.071 & 1.5 & & \\
\hline & far above average & 0.091 & 1.9 & & \\
\hline \multirow[t]{5}{*}{ perceived dwelling status (neighborhood): } & (omitted) far below average & & & & \\
\hline & below average & & & 0.112 & 1.4 \\
\hline & average & & & 0.087 & 2.7 \\
\hline & above average & & & 0.087 & 2.1 \\
\hline & far above average & & & 0.212 & 6.1 \\
\hline R-squared & & \multicolumn{2}{|c|}{0.1082} & \multicolumn{2}{|c|}{0.1084} \\
\hline No. of obs. & & \multicolumn{2}{|c|}{43317} & \multicolumn{2}{|c|}{43317} \\
\hline
\end{tabular}

Notes: OLS regressions. In column (1), we estimate Equation 3 and present the coefficients for the main variables. We estimate self-reported happiness of an individual $i$ at time $t$ as a function of his/her perceived dwelling status with respect to othe dwellings in his/her city as a 5 category variable as coded in the codebook, type of his/her dwelling, perceived social class as a 4 category variable as coded in the codebook, perceived relative income as a 5 category variable as coded in the codebook, reference group income and household income as a 5 category variable and are recoded in to 5 categories from the original, together with the same control variables used in Table 5 column 1 . In column (2), we estimate self-reported happiness of an individual $i$ at time $t$ as a function of his/her perceived dwelling status with respect to other dwellings in his/her neighborhood as a 5 category variable as coded in the codebook, type of his/her dwelling, perceived social class as a 4 category variable as coded in the codebook, perceived relative income as a 5 category variable as coded in the codebook, reference group income and household income as a 5 category variable and are recoded in to 5 categories from the original, together with the same control variables used in Table 5 , column 1. Self-reported happiness is measured on a scale 1-3 which corresponds to: "very happy," "pretty happy," and "not too happy." t-statistics are reported in absolute values. Robust standard errors are used. 


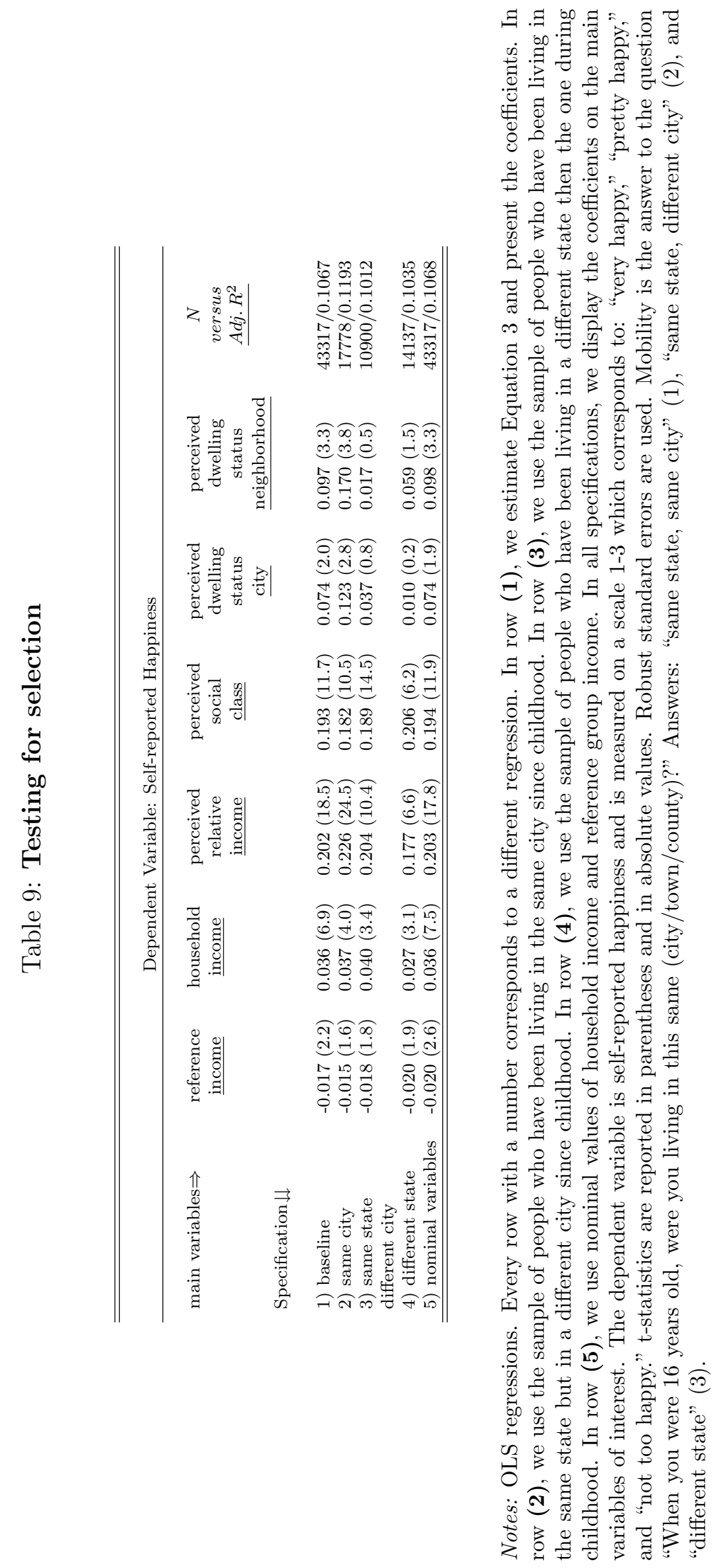




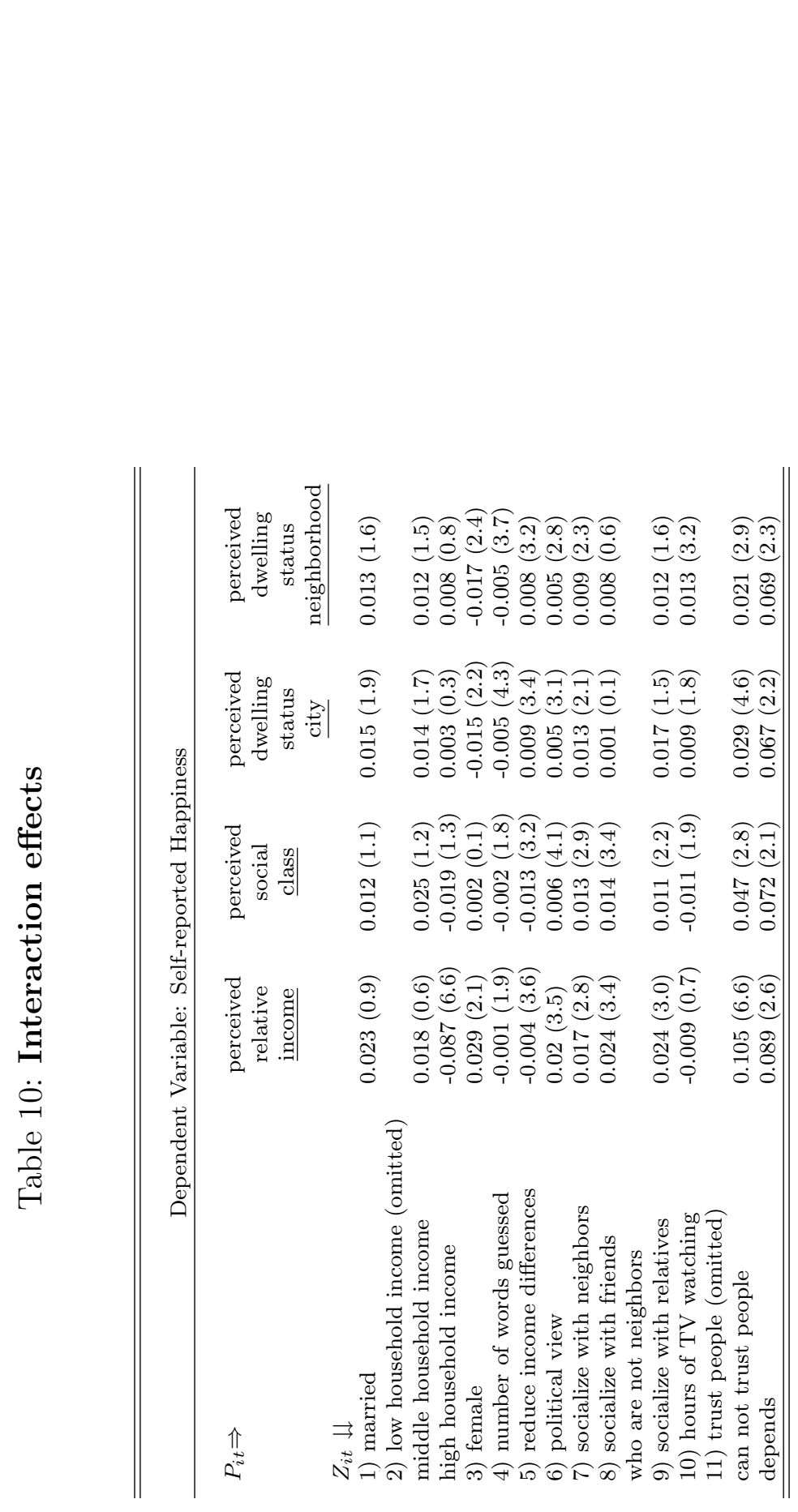

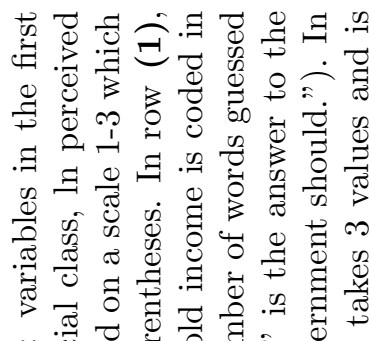

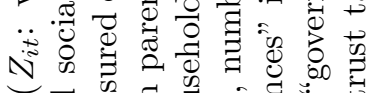

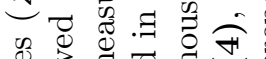

要

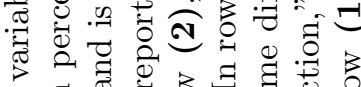

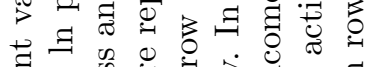

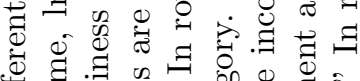

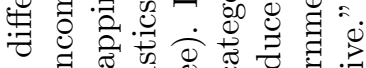

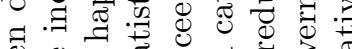

\&.

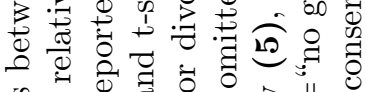

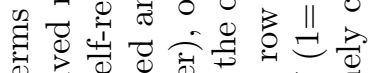

离.

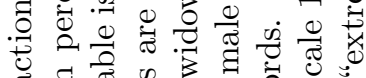

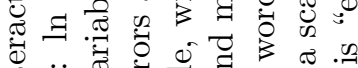

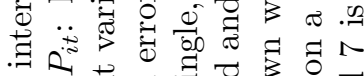

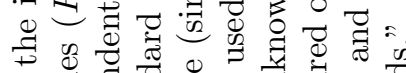

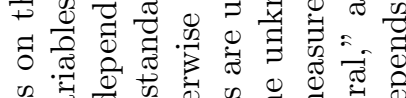

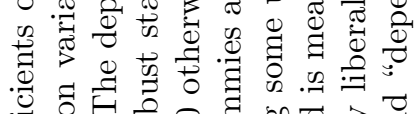

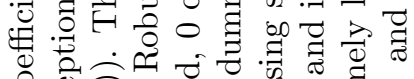

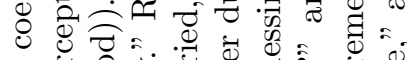

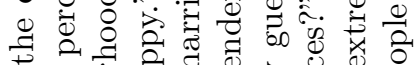

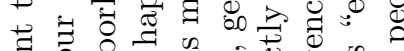

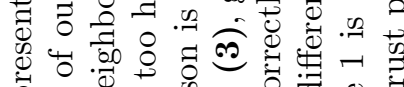

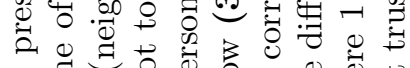

चี

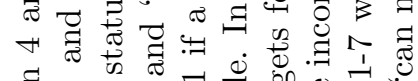

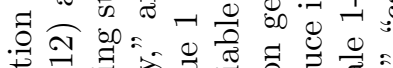

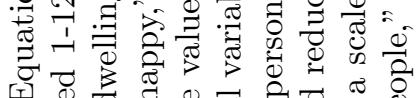

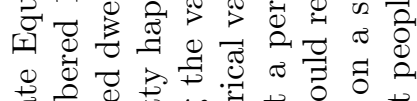

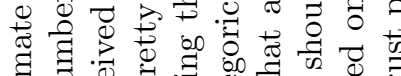

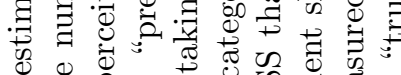

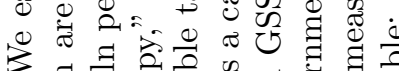

$\forall$ 켤

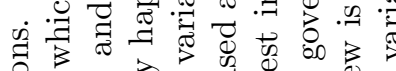

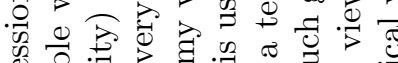

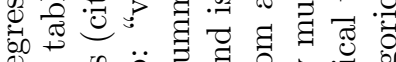

\&

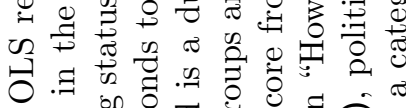

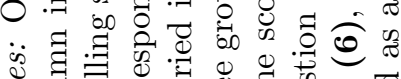

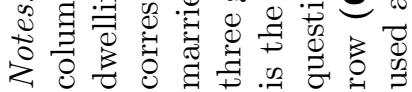




\section{APPENDIX}

\section{ROBUSTNESS TABLES.}

We present the summary statistics for the variables used in the paper in Tables A.1 and A.2. We report the means for the continuous variables (for instance, weekly working hours) and proportions (for instance, labor force status) for the categorical variables.

We estimate self-reported happiness of an individual $i$ at time $t$ as a function of his/her ln perceived dwelling status with respect to other dwellings in his/her neighborhood and city, type of his/her dwelling, ln perceived social class, ln occupational prestige, ln perceived relative income, ln reference group income and ln household income together with the following controls variables: dwelling ownership, ln weekly working hours, labor force status, sex, age, age square, race, years of education, ln household size, marital status, religion, ln population of the place of residence, region fixed effects, year fixed effects, occupation fixed effects, and industry fixed effects.

Since the question on perceptions about relative income is asked with respect to "American families in general" in the GSS, we use ln GDP per capita as the reference group income in specification two. In GDP per capita is negatively and significantly correlated with happiness, as expected, and it does not change any of our results. Then, in column 2 , we use ln sector level (1-digit) wages and ln sectoral level GDP as reference group income. Perception variables do not change but total sector GDP does not predict happiness. In the fourth specification, we run an OLS regression of household income on parent's education, spouse working hours, spouse labor force status and spouse occupational prestige. Then, we calculate the predicted income for everyone. We do the same in the fifth specification but now we use interval regression to calculate predicted income (original household income in the GSS is

in intervals). Our results are robust to these cases but now reference group income positively correlates with happiness. Lastly, we use ln sectoral wage and predicted income together and again the results do not change. One concern in these regressions can be multi-collinearity. However, Table A.4 shows that this is not the case and a perfect correlation does not exist among the independent variables used in the regression in Table A.3.

We conduct robustness checks in several ways in Table A.5. We control for ln personal income since perceptions might be correlated with personal income instead of household income. Our results again do not change. In the fourth specification, we estimate our model 
with ordered probit and find that the coefficients and the t-statistics are quite similar to the ones with OLS. We estimate our model for married and nonmarried samples and find that our results are again robust to different sub-samples. Next, we use levels of the income and status variables instead of logarithms in specification seven. In specifications eight and nine, we control for own and spouse's socio-economic status which might affect our main variables of interest and happiness at the same time. The results again are robust.

We conduct more robustness checks in Table A.6. We use perceived social class as a 10 category variable and then use happiness as a 7 category variable but our results do not change (these variables are often missing). In the third specification, we consider using "daily happiness" instead of general happiness. We find that daily happiness is not correlated with household income nor with actual relative income. However, perceptions about relative income and social class can predict daily happiness. Moreover, daily happiness is a 4 category variable which provides an opportunity to control for personal bias in choosing the middle category in odd numbered questions. In the fourth specification, we use residual happiness instead of actual happiness as the dependent variable. By doing so, we try to control for any collinearity problem between income and other variables since residual happiness is calculated after the regression of happiness on household income and other variables in the baseline regression. For example, if income aspirations are correlated with perceptions as well as happiness, this might bias our results. Therefore, we control for income aspirations. We also use the distance from poverty line as a measure of actual relative income and the results are robust to this (this variable is generated by the GSS). In addition, we control for spouse's work status and use interval regressions to assign income levels from income intervals, assuming that income is log-normally distributed, rather than taking the midpoint in their conversion of categorical income categories to point estimates. The results are robust to these permutations.

It is believed that childhood and past life events have effects on the current well-being of an individual. These events might also be correlated with perceptions which can bias our estimates. Therefore, we control for these variables in the regressions in Table A.7. We find that individuals perceptions about their family income during childhood matters. It appears that the size of the coefficient on current perceived relative income declines with the inclusion of perceptions during childhood which suggests that there might be some persistence in perceptions during the life cycle (One might think of using perceptions during 
Table A.1: Other independent variables' means, proportions, and standard deviations

\begin{tabular}{lrr} 
Variable & mean & stdev \\
\hline \hline & 2.2 & 0.63 \\
happiness & 10.6 & 0.99 \\
ln reference group income & 9.9 & 0.98 \\
ln household income & 9.5 & 1.08 \\
ln personal income & 2.9 & 0.83 \\
perceived relative income & 2.5 & 0.65 \\
perceived social class & 2.8 & 0.86 \\
perceived relative income & & \\
when 16 years old & 45.2 & 17.52 \\
age & 62.8 & 0.04 \\
own dwelling & 35.0 & 0.03 \\
rent dwelling & 2.2 & 0.01 \\
other dwelling & 61.9 & 0.02 \\
employed & 3.0 & 0.01 \\
unemployed & 35.1 & 0.02 \\
not in the labor force & 43.9 & 0.02 \\
male & 56.1 & 0.02 \\
female & 82.7 & 0.02 \\
white & 13.8 & 0.02 \\
black & 3.5 & 0.01 \\
other & 12.6 & 3.2 \\
years of education & 1.9 & 1.81 \\
children & 2.7 & 1.54 \\
household size & 55.5 & 0.02 \\
married & 45.5 & 0.02 \\
not married & 3.1 & 0.62 \\
dwelling relative to neighborhood & 3.0 & 0.78 \\
dwelling relative to city & & \\
\hline \hline & & \\
\hline
\end{tabular}

Notes: This table shows the summary statistics of the variables used in the paper. Means are reported for the continuous variables and proportions (for instance, 61.9 equals to the number of people who are employed divided by the sum of people who are employed, unemployed, and not in the labor force.) are reported for categorical variables.

childhood as an instrument for current perceptions however the childhood perceptions are asked currently. Hence, current personal characteristics might influence the answer to this question. Therefore, we only consider using it as another explanatory variable for the current well-being.) Considering deaths, hospitalizations and divorces, we find that past events have strong influence on current happiness however we find evidence for adaptation. For instance, the influence of death of spouse in the last year is higher than the death fours ago or more than 6 years ago. Interestingly, people are affected more by the death of the mother than the father. There seems to be some adaptation to perceptions and also income shocks in the United States. We only display the coefficients on the extra controls in the table but our results are robust to the inclusion of past life events. 
Table A.2: Other independent variables' means, proportions, and standard deviations

\begin{tabular}{lrr} 
Variable & mean & stdev \\
\hline \hline & & \\
Protestant & 60.9 & 0.02 \\
Catholic & 24.6 & 0.02 \\
Jewish & 21.0 & 0.01 \\
none & 9.26 & 0.01 \\
other denominations & 1.9 & 0.01 \\
Buddhist & 0.1 & 0.01 \\
Muslim & 0.1 & 0.01 \\
Orthodox-Christian & 0.1 & 0.01 \\
Christian & 0.5 & 0.01 \\
Inter-Nondenominational & 0.2 & 0.01 \\
mobility: & & \\
same city & 41.4 & 0.02 \\
same state, different city & 25.5 & 0.02 \\
different state & 33.1 & 0.02 \\
ln occupational prestige & 3.7 & 0.37 \\
number of words guessed & 6.0 & 2.16 \\
political view & 4.1 & 1.35 \\
opinion on income differences & 4.3 & 1.96 \\
health & 3.0 & 0.85 \\
weekly working hours & 41.2 & 14.07 \\
household size & 3.5 & 2.19 \\
ln own socio-economic index & 3.80 & 0.40 \\
ln spouse socio-economic index & 3.84 & 0.39 \\
\hline \hline
\end{tabular}

Notes: This table shows the summary statistics of the variables used in the paper. Means are reported for the continuous variables and proportions (for instance, 41.4 equals to the number of people who still live in the same city divided by the sum of people who live in the same city, same state but different city, and different state.) are reported for categorical variables. 


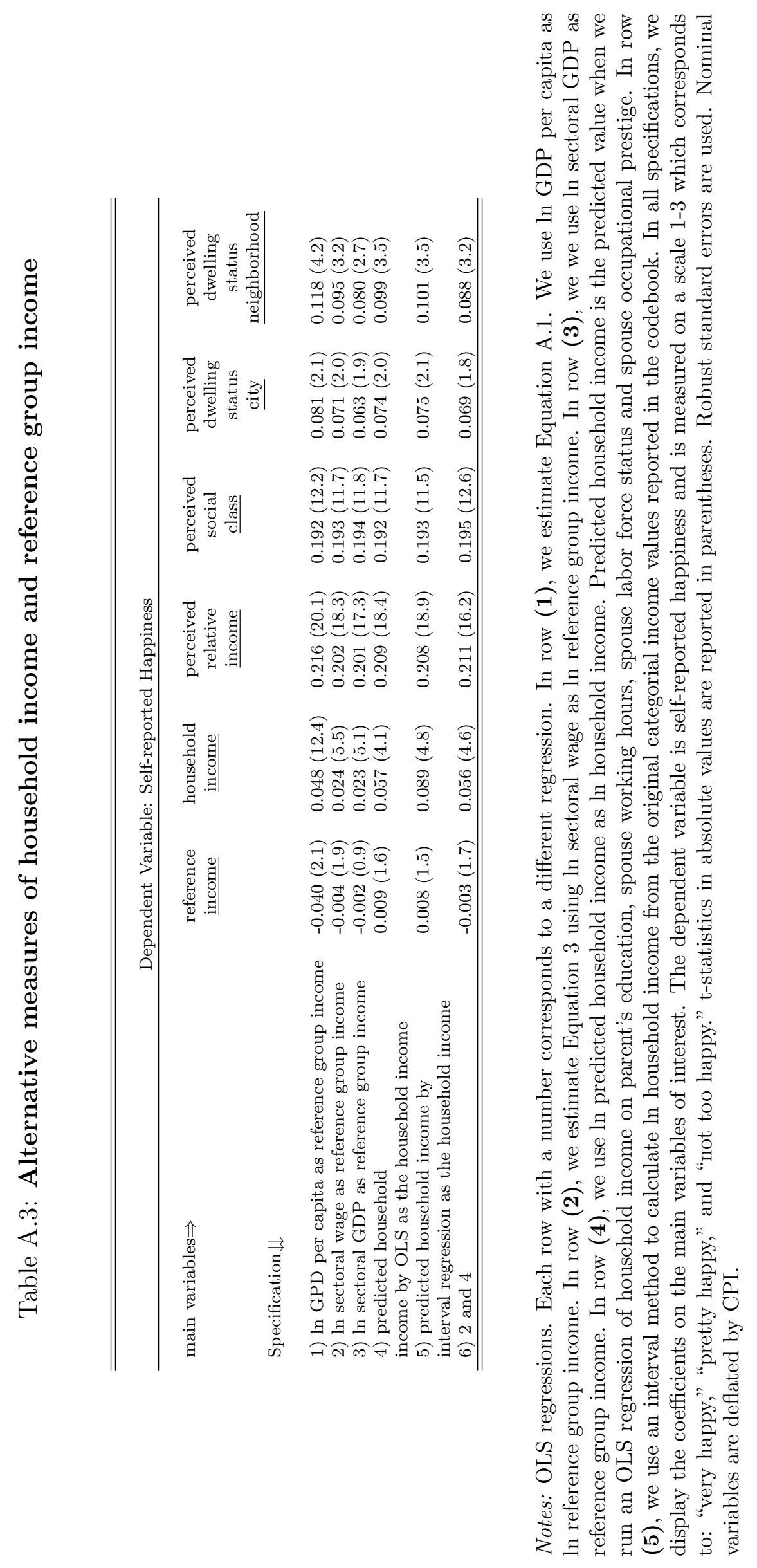




\section{Table A.4: Correlation of instruments with main variables}

\begin{tabular}{lllll}
\hline \hline & $\begin{array}{l}\text { ln household } \\
\text { income }\end{array}$ & $\begin{array}{l}\text { ln reference } \\
\text { group } \\
\text { income }\end{array}$ & $\begin{array}{l}\text { ln perceived } \\
\text { relative } \\
\text { income }\end{array}$ & $\begin{array}{l}\text { ln perceived } \\
\text { social } \\
\text { class }\end{array}$ \\
ln GDP per capita & 0.02 & 0.46 & 0.02 & 0.01 \\
ln sectoral wage & 0.03 & 0.17 & 0.01 & 0.04 \\
ln sectoral GDP & 0.05 & 0.19 & 0.03 & 0.03 \\
\hline \hline
\end{tabular}

Notes: We show the correlations among the instruments used in Table A.3 and ln household income, ln reference group income, ln perceived relative income, and ln perceived social class. All variables are in logarithms. 


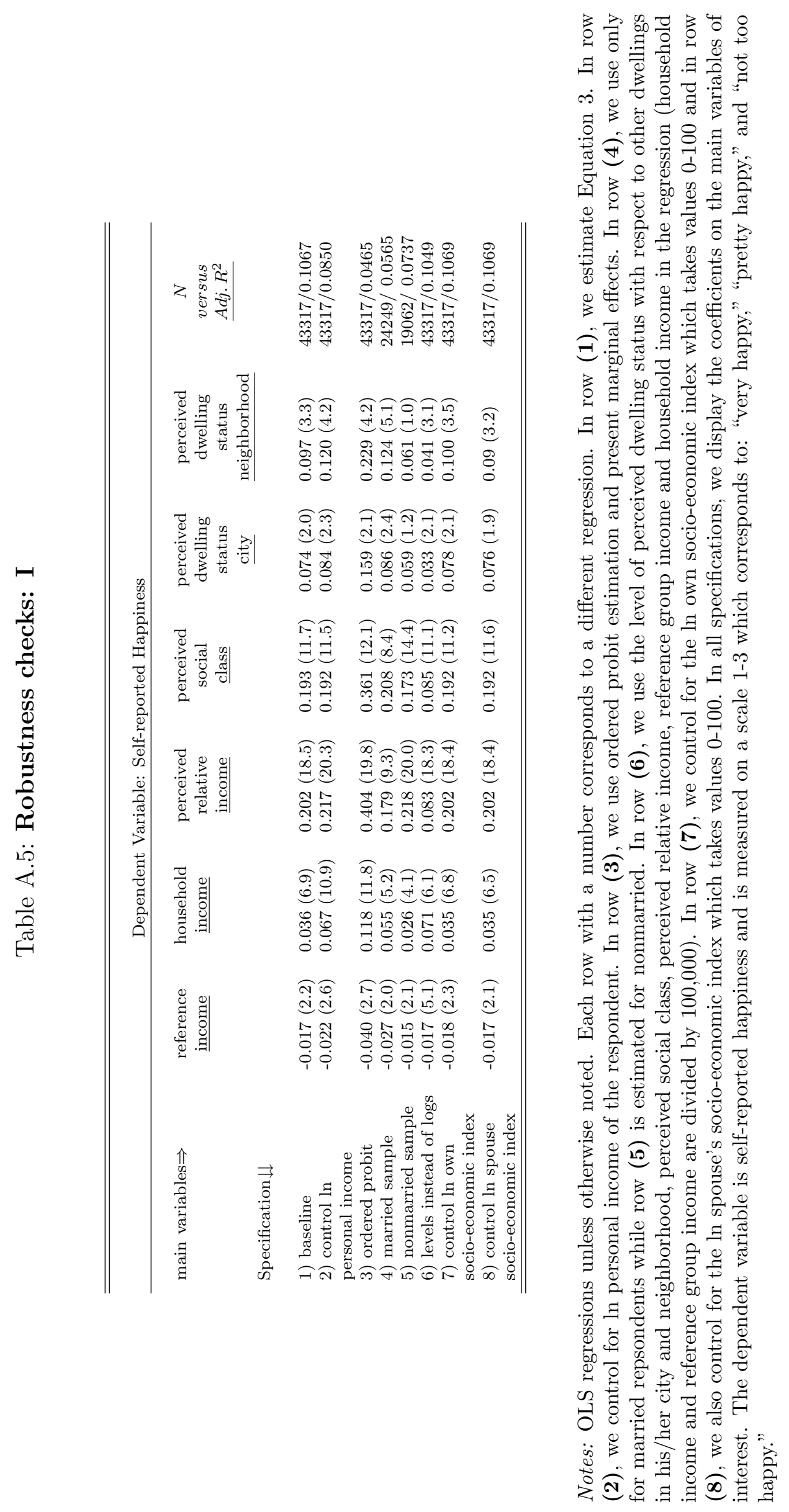




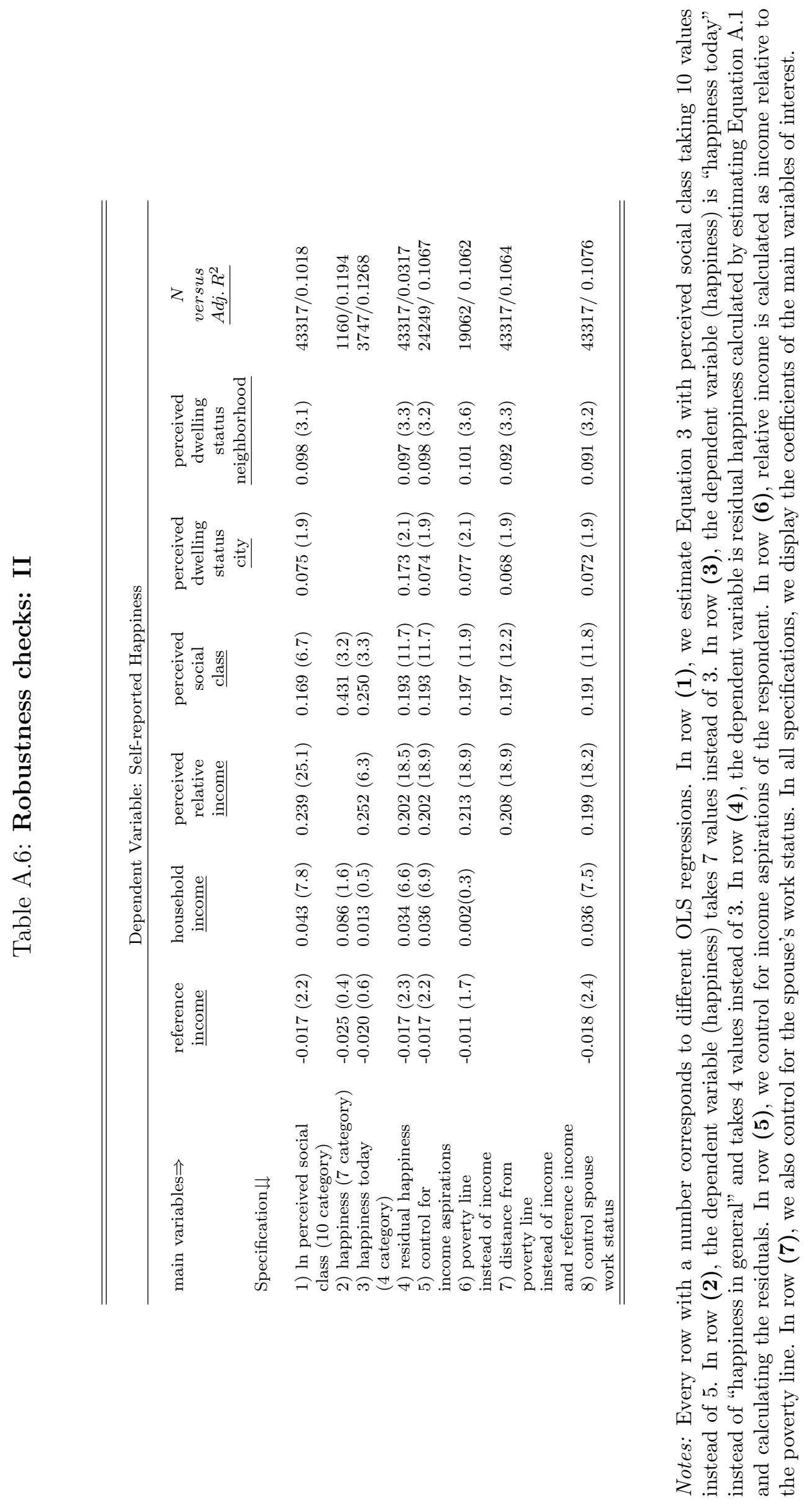


Table A.7: Controlling for past life events and adaptation

Dependent Variable: Self-reported Happiness

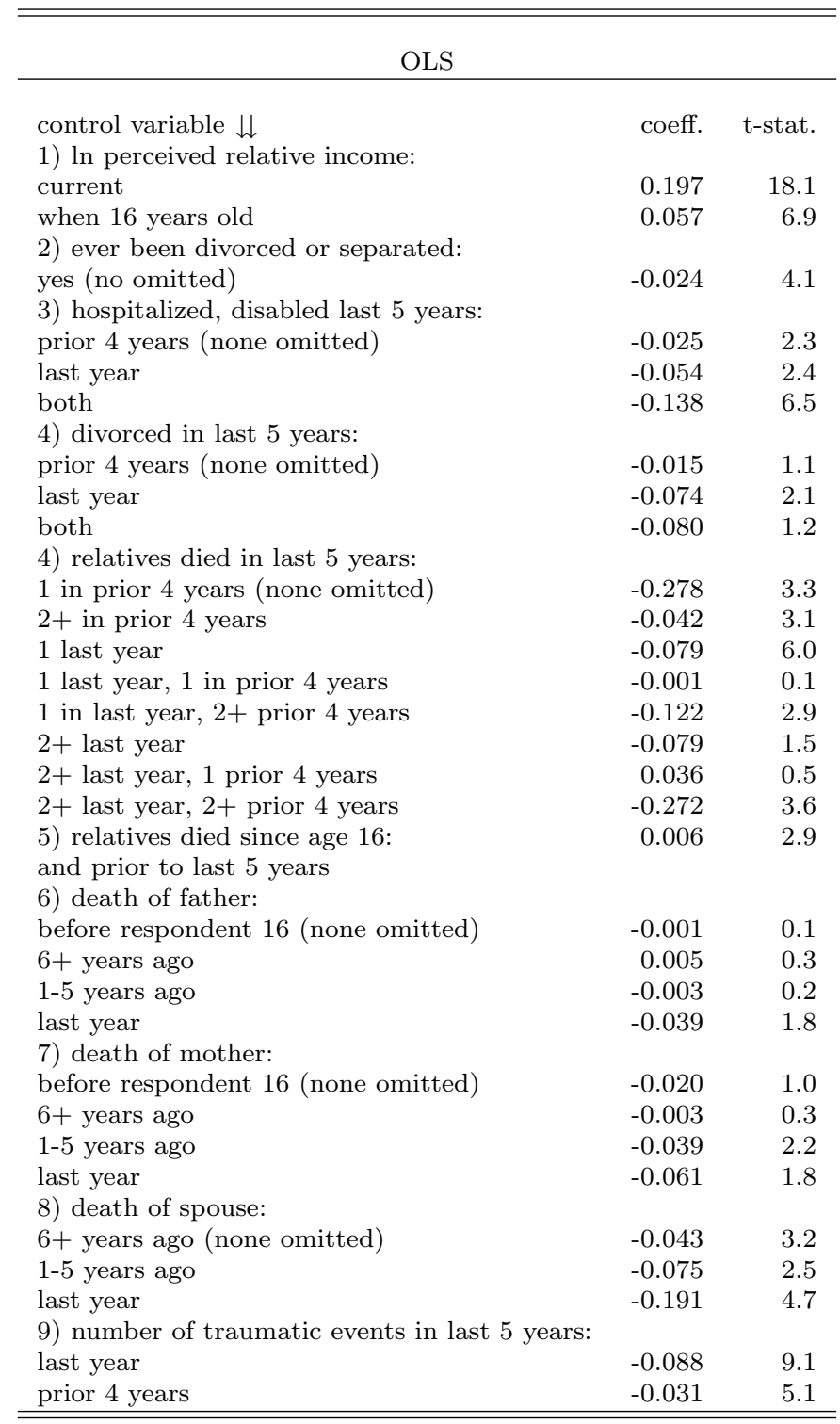

Notes: Every row with a number corresponds to a different regression. In each row, we estimate Equation 3 using OLS adding new control variables. For instance, in row 1, we also control for ln perceived relative income when the respondent was 16. In the first specification, we control for father's and mother's occupational prestige, region dummies, and type of place lived when respondent was 16 years old. Occupational prestige scores are variables in logs (original 0-100) and type of place lived is a categorical variable taking 6 values where $1=$ country nonfarm, $2=$ farm, $3=$ town less than 50000 people, $4=50000-250000$ people, $5=$ big-city suburb, $6=$ city more than 250000 people. Traumatic events are defined as unemployment, death, divorce/seperation, or hospitalized/disabled. 


\section{VARIABLES USED IN THE PAPER:}

Self-reported happiness: The answer to question 157 in the 2004 GSS codebook: "Taken all together, how would you say things are these days - would you say that you are very happy, pretty happy, or not too happy?" Answer: "not too happy" (1), "pretty happy" (2), "very happy" (3), and "don’t know" (missing), no answer (missing), not applicable (missing).

Perceived relative income: The answer to question 188 in the 2004 GSS codebook: "Compared with American families in general, would you say your family income is far below average, below average, average, above average, or far above average? Probe: Just your best guess." Answer: "far below average" (1), "below average" (2), "average" (3), "above average" (4), "far above average" (5), and "don’t know" (missing), no answer (missing), not applicable (missing).

Perceived relative income when 16 years old: The answer to question 30 in the 2004 GSS codebook: "Thinking about the time when you were 16 years old, compared with American families in general then, would you say your family income is far below average, below average, average, above average, or far above average? Probe: Just your best guess." Answer: "far below average" (1), "below average" (2), "average" (3), "above average" (4), "far above average" (5), and "don't know" (missing), no answer (missing), not applicable (missing).

Perceived social class: The answer to question 185-A in the 2004 GSS codebook: "If you were asked to use one of four names for your social class, which would you say you belong in: the lower class, the working class, the middle class, or the upper class?" Answer: "lower class" (1), "working class," (2) "middle class," (3) "upper class," (4) and "don’t know" (missing), no answer (missing), not applicable (missing).

Household income: 1) We created a continuous family income variable using the mid-point method to the the answer to question 37 in the 2004 GSS codebook: "In which of these groups did you total family income, from all sources, fall last year before taxes, that is? Just tell me the letter." Answer: Under 1000 (1), 1000-2999 (2), 3000-3999 (3), 4000-4999 (4), 5000-5999 (5), 6000-6999 (6), 7000-7999 (7), 8000-8999 (8), 10000-14999 (9), 15000-19999 (10), 20000-24999 (11), 25000 and over (12), refused (missing), don’t know (missing), no answer (missing), not applicable (missing). 2) GSS generated, variable number 1437 in the 2004 GSS codebook, family income on 1972-2004 surveys in constant dollars (base 1986)

Health status: The answer to question 159 in the 2004 GSS codebook: "Would you say your own health, in general, is excellent, good, fair, or poor?" Answer: "Excellent" (4), "good" (3), "fair" (2), "poor" (1), and "don’t know" (missing), no answer (missing), not applicable (missing).

Marital status: The answer to question 4 in the 2004 GSS codebook: "Are you currently-married, widowed, divorced, separated, or have you never been married?" Answer: "married" (1), "widowed" (2), "divorced" (3), "separated" (4), "never married" (5), and no answer (missing). We recode this variable as follows: married $=1$, and not married $=2,3,4,5$. 
Labor force status: The answer to question 1 in the 2004 GSS codebook: "Last week were you working full-time, part-time, going to school, keeping house, or what?" Answer: "working full-time" (1), "working part-time" (2), "with a job, but not at work because of temporary illness, vacation, strike" (3), "unemployed, laid off, looking for work" (4), "retired" (5), "in school" (6), "keeping house" (7), "other" (8), and no answer (missing). We recode this variable as follows: employed $=1,2,3$ unemployed $=4$, and not in the labor force $=5,6,7,8$.

Working hours: The answer to question 1-A in the 2004 GSS codebook: "If working full or part-time: How many hours did you work last week, at all jobs? " Answer is the number of hours, no answer (missing), not applicable (missing).

Sex: The answer to question 23 in the 2004 GSS codebook: Coded by the interviewer. "Male" (1) and "female" (2).

Race: The answer to question 24 in the 2004 GSS codebook: "What race do you consider yourself?" Answer: "white" (1), "black" (2), "other" (3), and not applicable (missing).

Education: The answer to question 15 in the 2004 GSS codebook: Coded as the number of years of schooling (maximum is 20) and don't know (missing), no answer (missing).

Children: The answer to question 12 in the 2004 GSS codebook: 'How many children have you ever had? Please count all that were born alive at any time (including any had from a previous marriage" Answer: 0, $1,2,3,4,5,6,7,8$ or more, don't know (missing), no answer (missing).

Age: The answer to question 13 in the 2004 GSS codebook: Coded as the number of years from birth, don't know (missing), no answer (missing).

Household size: The answer to question 34 in the 2004 GSS codebook: Coded as the number of household members (1-16), no answer (missing).

Region: The region of interview, question 51 in the 2004 GSS codebook: New England (1), Middle Atlantic (2), East North Central (3), West North Central (4), South Atlantic (5), East South Central (6), West South Central (7), Mountain (8), Pacific (9). (See Question 26 in the 2004 GSS codebook for a listing of the states within regions.)

Occupational prestige: The prestige scores assigned to occupations were taken from rating systems developed at (NORC) in a project on occupation prestige directed by Robert W. Hodge, Paul S. Siegel, and Peter H. Rossi. This concept of prestige is defined as the respondents' estimation of the social standing of occupations. The prestige scores in the Hodge-Siegel-Rossi and GSS studies were generated by asking respondents to estimate the social standing of occupations in a nine-step ladder, printed on cardboard and presented to the respondent. It is constructed from two variables: 1) Occupational prestige score 1974-1992 on page 54 in the 2004 GSS codebook 2) Occupational prestige score 1992-2004 on page 57 in the 2004 GSS codebook. (See page 2050 for the construction of the prestige scores in the 2004 GSS Appendix.) 
Occupation: One digit occupation categories for the respondents. It is constructed from two variables: 1) Occupational classifications 1974-1992 on page 54 in the 2004 GSS codebook 2) Occupational classifications 1992-2004 on page 56 in the 2004 GSS codebook. (See pages 2031 and 2068 for the subcategories of occupational categories in the 2004 GSS Appendix.)

Industry: One digit industry categories for the respondents. It is constructed from two variables: 1) Occupational classifications 1974-1992 on page 56 in the 2004 GSS codebook 2) Occupational classifications 1992-2004 on page 57 in the 2004 GSS codebook. (See pages 2055 and 2068 for the subcategories of occupational categories in the 2004 GSS Appendix.)

TV hours: The answer to question 242 in the 2004 GSS codebook: "On the average day, about how many hours do you personally watch television?" Answer: number of hours from 0-24, and don't know (missing), no answer (missing), not applicable (missing). Reference for the variables and the explanations:

Political view: The answer to question 66-A in the 2004 GSS codebook: "We hear a lot of talk these days about liberals and conservatives. I am going to show you a seven-point scale on which the views that people might hold are arranged from extremely liberal-point 1- to extremely conservative-point 7 . Where would you place yourself on this scale?" Answer: "Extremely liberal" (1), "liberal" (2), "slightly liberal" (3), "moderate, middle of the road" (4), "slightly conservative" (5), "conservative" (6), "extremely conservative" (7), and "don't know" (missing), no answer (missing), not applicable (missing).

Socialization variables: The answers to question 173 in the 2004 GSS codebook: "Would you use this card and tell me which answer comes closest to how often you do the following things?" A) "Spend a social evening with relatives," B) "Spend a social evening with someone who lives in your neighborhood," C) "Spend a social evening with friends who live outside the neighborhood." Answer: "Never" (1), "about once a year" (2), "several times a year" (3), "about once a month" (4), "several months a year" (5), "once or twice a week" (6), "almost every day" (7), and "don't know" (missing), no answer (missing), not applicable (missing).

Dwelling variables: Dwelling type: The variable 1469 (interviewer coded) in the 2004 GSS codebook: Trailer (1), detached single family house (2), 2-family house, 2 units side by side (3), 2-family house, 2 units one above the other (4), detached 3-4 family house (5), row house (6), apartment house, 3 stories or less (7), apartment house, 4 stories or more (8), apartment in a partly commercial structure (9), other (10), don't know (missing), no answer (missing), not applicable (missing). A): The answers to question 1470-A in the 2004 GSS codebook: "Compared to apartments/houses in the neighborhood, would you say the house/apartment was..." B) :The answers to question 1470-B in the 2004 GSS codebook: "Compared to apartments/houses in the city/town/county, would you say the house was..." Answers: "far below average" (1), "below average" (2), "average" (3), "above average" (4), "far above average", and (5), "no answer" (missing), not applicable (missing). Dwelling own: The answers to question 1471 in the 2004 GSS codebook: " (Do you/does your family) own your (home/apartment), pay rent, or what?" Answer: "own or is buying" (1), "pays rent" (2), "other" (3), and "don't know" (missing), no answer (missing), not applicable (missing). 
Mobility: The answers to question 26-A in the 2004 GSS codebook: "When you were 16 years old, were you living in this same (city/town/county)?" Answer: "same state, same city" (1), "same state, different city" (2), "different state" (3), and "don't know" (missing), no answer (missing).

Religion: The answer to question 104 in the 2004 GSS codebook: "What is your religious preference? Is it Protestant, Catholic, Jewish, some other religion, or no religion?" Answer: "Protestant" (1), "Catholic" (2), "Jewish" (3), "none" (4), "other denominations" (5), "Buddhism" (6), "Hinduism" (7), "other Eastern" (8), "Moslem/Islam" (9), "Orthodox-Christian" (10), "Christian" (11), "Native American" (12), "Inter-Nondenominational" (13), and "don’t know" (missing), no answer (missing).

Socio-Economic Index scores: Socio-economic indexes of own (variable 1506 in the 2004 GSS codebook) and the spouse (variable 1510 in the 2004 GSS codebook) taking values 0-100.

Reference for the variables and the explanations:

Webpage: 1972-2004 GSS Codebook http://www.deakin.edu.au/c̃ahit/appendix.pdf

Webpage: 1972-2004 GSS Appendix http://www.deakin.edu.au/c̃ahit/codebook.pdf 